Federal Reserve Bank of Minneapolis

Research Department Staff Report 434

August 2009

\title{
A Parsimonious Macroeconomic Model for Asset Pricing*
}

\author{
Fatih Guvenen \\ University of Minnesota, \\ Federal Reserve Bank of Minneapolis, \\ and NBER
}

\begin{abstract}
I study asset prices in a two-agent macroeconomic model with two key features: limited stock market participation and heterogeneity in the elasticity of intertemporal substitution in consumption (EIS). The model is consistent with some prominent features of asset prices, such as a high equity premium; relatively smooth interest rates; procyclical stock prices; and countercyclical variation in the equity premium, its volatility, and in the Sharpe ratio. In this model, the risk-free asset market plays a central role by allowing non-stockholders (with low EIS) to smooth the fluctuations in their labor income. This process concentrates non-stockholders' labor income risk among a small group of stockholders, who then demand a high premium for bearing the aggregate equity risk. Furthermore, this mechanism is consistent with the very small share of aggregate wealth held by non-stockholders in the US data, which has proved problematic for previous models with limited participation. I show that this large wealth inequality is also important for the model's ability to generate a countercyclical equity premium. When it comes to business cycle performance the model's progress has been more limited: consumption is still too volatile compared to the data, whereas investment is still too smooth. These are important areas for potential improvement in this framework.
\end{abstract}

\footnotetext{
*Email: guvenen@umn.edu; http://www.econ.umn.edu/ guvenen. First version: September 3, 2002. For helpful conversations and comments, I thank Daron Acemoglu, John Campbell, V.V. Chari, Jeremy Greenwood, Lars Hansen, Urban Jermann, Narayana Kocherlakota, Per Krusell, Martin Lettau, Debbie Lucas, Sydney Ludvigson, Rajnish Mehra, Martin Schneider, Tony Smith, Kjetil Storesletten, Ivan Werning, Amir Yaron, and especially a co-editor and five anonymous referees, as well as seminar participants at Duke University (Fuqua), Massachusetts Institute of Technology, Ohio State University, University of Montréal, University of Pittsburgh, University of Rochester, UT-Austin, UT-Dallas, NBER Economic Fluctuations and Growth meetings, NBER Asset Pricing meetings, the SED conference, and the AEA winter meetings. Financial support from the National Science Foundation under grant SES-0351001 is gratefully acknowledged. The views expressed herein are those of the author and not necessarily those of the Federal Reserve Bank of Minneapolis or the Federal Reserve System.
} 


\section{Introduction}

Since the 1980s, a vast body of empirical research has documented some interesting and puzzling features of asset prices. For example, Mehra and Prescott (1985) have shown that the equity premium observed in the historical US data was hard to reconcile with a canonical consumption-based asset pricing model, and as it later turned out, with many of its extensions. A parallel literature in financial economics has found that the equity premium was predictable by a number of variables including the dividend yield, challenging the long-held view that stock returns follow a martingale (Campbell and Shiller (1988)). Other studies have documented that the expected equity premium, its volatility, and the ratio of the two - the conditional Sharpe ratio - move over time following a countercyclical business cycle pattern (Schwert (1989), and Chou, Engle, and Kane (1992)).

In this paper, I ask if these asset pricing phenomena can be explained in a parsimonious macroeconomic model with two key features: limited participation in the stock market and heterogeneity in the elasticity of intertemporal substitution in consumption (EIS). The limited nature of stock market participation and the concentration of stock wealth even among stockholders is well documented. For example, until the 1990s more than two-thirds of US households did not own any stocks at all, while the richest $1 \%$ held $48 \%$ of all stocks (Poterba and Samwick (1995), and Investment Company Institute (2002)). As for the heterogeneity in preferences, the empirical evidence that I review in Section 3 indicates that stockholders have a higher EIS than non-stockholders. The interaction of these two features is important, as will become clear below.

I choose the real business cycle model as the foundation that I build upon, to provide a contrast with the poor asset pricing implications of that framework that are well-known, which helps to highlight the role of the new features considered in this paper. Specifically, I study an economy with competitive markets and a neoclassical production technology subject to capital adjustment costs. There are two types of agents. The majority of households (first type) do not participate in the stock market where claims to the firm's future dividend stream are traded. However, a risk-free bond is available to all households, so non-stockholders can also accumulate wealth and smooth consumption intertemporally. Finally, consistent with empirical evidence, non-stockholders are assumed to have a low EIS, whereas stockholders have a higher elasticity. To clarify the role played by different preference parameters, I employ Epstein-Zin preferences and disentangle risk aversion from the EIS. I find that heterogeneity

in risk aversion plays no essential role, whereas heterogeneity in the EIS (and especially the low EIS of non-stockholders) is essential, for the results of this paper. 
I first examine a benchmark version of the model in which labor supply is inelastic. The calibrated model is consistent with some salient features of asset prices, such as a high equity premium with a plausible volatility, and a low average interest rate. Furthermore, the variability of the interest rate is very low in the US data, which has proved challenging to explain for some previous models that have otherwise successful implications. The standard deviation of the risk-free rate is about $4 \%-6.5 \%$ in the present model, which is still higher than in the US data, but quite low compared to some of these earlier studies. So, the present paper provides a step in the right direction as far as interest rate volatility is concerned.

Although there are now several papers that have made progress in explaining these unconditional moments in the context of production economies, ${ }^{1}$ some aspects of asset price dynamics have proved more difficult to generate. The present model is consistent with the procyclical variation in stock prices; the mean reversion in the equity premium; and the countercyclical variation in the expected equity premium, in its volatility, and in the conditional Sharpe ratio. While the model also reproduces the long-horizon predictability of the equity premium, the degree of predictability is quantitatively small compared to the data.

This paper, as well as earlier models with limited participation, build on the empirical observation, first made by Mankiw and Zeldes (1991), that stockholders' consumption growth is more volatile (and more highly correlated with returns) than that of non-stockholders. Therefore, a high equity premium can be consistent with the relatively smooth per capita consumption process in the US data, since stockholders only make up a small fraction of the population. Existing theoretical models differ precisely in the economic mechanisms they propose for generating this high volatility of stockholders' consumption growth.

The mechanism in this paper differs from earlier studies (most notably, Saito (1995) and Basak and Cuoco (1998)) in some crucial ways. In particular, in these earlier models nonstockholders consume out of wealth, which they must invest in the bond market given the absence of any other investment opportunity. As a result, each period stockholders make interest payments to non-stockholders, which leverages the capital income of stockholders, thereby amplifying their consumption volatility. Although this is a potentially powerful mechanism, it only works quantitatively if these interest payments are substantial, which in turn requires non-stockholders to own a substantial fraction of aggregate wealth. But, in reality, non-stockholders own only one-tenth of aggregate wealth in the United States, and this counterfactual implication has been an important criticism raised against these models.

\footnotetext{
${ }^{1}$ Jermann (1998), Boldrin, Christiano, and Fisher (2001), Danthine and Donaldson (2002), Storesletten, Telmer and Yaron (2007), and Uhlig (2006), among others.
} 
One contribution of this paper is to propose a new economic mechanism, which avoids this counterfactual implication. Specifically, the mechanism results from the interaction of three factors. First, non-stockholders receive labor income every period, which is stochastic, and trade in the bond market for smoothing the fluctuations in their consumption. Second, because of their low EIS, non-stockholders have a stronger desire for consumption smoothingand therefore need the bond market much more - than stockholders (who have a higher EIS and an additional asset for consumption smoothing purposes). However, and third, since the source of risk is aggregate, the bond market cannot eliminate this risk and merely reallocates it across agents. In equilibrium, stockholders make payments to non-stockholders in a countercyclical fashion, which serves to smooth the consumption of non-stockholders and amplifies the volatility of stockholders, who then demand a large premium for holding aggregate risk. As shown in Section 6.3, this mechanism is consistent with a very small wealth share of non-stockholders precisely because it is the cyclical nature of interest payments that is key, and not their average amount (which can very well be zero).

The same mechanism also explains why the equity premium is countercyclical. Essentially, because non-stockholders have very low wealth they become effectively more risk averse during recessions when their wealth falls even further (because with incomplete markets value functions have more curvature at low wealth levels.) This is not the case for stockholders who hold substantially more wealth. Consequently, during recessions, non-stockholders demand more consumption smoothing, which strengthens the mechanism described above -i.e., increased trade in the bond market, more volatile consumption growth for stockholdersgenerating a higher premium in recessions. In Section 5, I quantify the contribution of these channels to both the level and countercyclicality of the equity premium.

I also investigate the extent to which labor supply choice can be endogenized without compromising overall performance. Cobb-Douglas utility does not appear to be suitable for this task: it results in a deterioration of asset pricing results and generates labor hours much smoother than in the data. One reason for these results is that these preferences do not allow an independent calibration of the EIS and the Frisch labor supply elasticity, which are both crucial for my analysis. This poor performance perhaps does not come as a surprise in light of the earlier findings: for example, Lettau and Uhlig (2000), Boldrin et al. (2001, hereafter $\mathrm{BCF}$ ), and Uhlig (2006) uncover various problems generated by endogenous labor supply in asset pricing models and identify certain labor market frictions that successfully overcome these difficulties. Incorporating the same frictions into the model with Cobb-Douglas utility could also improve its performance, although this is beyond the scope of the present paper. 
Next I consider the utility specification first introduced by Greenwood, Hercowitz, and Huffman (1988, GHH) and find that it performs better: it preserves the plausible asset pricing implications of the model with inelastic labor fairly well, and generates business cycle implications in the same ballpark as existing macroeconomic models. While these results suggest that GHH preferences could provide a promising direction for endogenizing labor supply in this class of models, there is still much room for improvement: consumption volatility remains significantly higher than in the US data, whereas investment volatility is still too low. Therefore, the progress made by this model has been rather limited in tackling these well-known shortcomings shared by many macro-asset pricing models. A potentially fruitful approach could be to introduce certain labor market frictions, such as wage rigidities, that have been found to improve asset pricing models along these dimensions (Uhlig (2006)).

This paper is related to a growing literature that builds models for jointly studying asset prices and macroeconomic behavior. In addition to the papers cited in footnote 1, Danthine and Donaldson (2002) construct an entrepreneur-worker model, in which the worker lives hand-to-mouth and there is no labor supply choice. In this environment, labor contracts between the two agents act as "operational leverage" and affect asset prices in a way that is similar to limited participation. Storesletten, Telmer, and Yaron (2007) build a heterogeneous-agent model and show that persistent idiosyncratic shocks with countercyclical innovation variance generate plausible unconditional moments. As noted earlier, one difference of my paper is the focus on the dynamics of asset prices, which is not studied in these papers. Finally, in terms of integrating recursive preferences into macro-asset pricing models, an important precursor is Tallarini (2000), who shows how one can fix the EIS and increase the risk aversion in the standard RBC model to generate a high market price of risk without causing a deterioration in business cycle properties. The present paper goes one step further by introducing limited participation, preference heterogeneity, and adjustment costs and generates a high equity premium with a risk aversion that is much lower than in Tallarini (2000). Other notable contributions that are contemporaneous to the present paper include Campanale, Castro, and Clementi (2007) and Gomes and Michaelides (2008), who build full blown macro-asset pricing models with recursive preferences; and Uhlig (2007), who provides a convenient log-linear framework for asset pricing with recursive preferences, labor-leisure choice, and long-run risk. I further discuss some of these papers later below.

The paper organized as follows. The next section presents the model and the parametrization is discussed in Section 3. Sections 4 and 5 contain the asset pricing results and the mechanism. The macro implications are presented in Section 6 and Section 7 concludes. 


\section{The Model}

Households. The economy is populated by two types of agents who live forever. The population is constant and is normalized to unity. Let $\mu \in(0,1)$ denote the measure of the second type of agents (who will be called "stockholders" later). Consumers are endowed with one unit of time every period, which they allocate between market work and leisure. I consider three different preference specifications in this paper that can be written as special cases of the following Epstein-Zin recursive utility function:

$$
U_{t}^{i}=\left[(1-\beta) u^{i}\left(c_{t}, 1-l_{t}\right)+\beta\left(E_{t}\left(U_{t+1}^{i}\right)^{1-\alpha^{i}}\right)^{\frac{1-\rho^{i}}{1-\alpha^{i}}}\right]^{\frac{1}{1-\rho^{i}}}
$$

for $i=h, n$, where throughout the paper the superscripts $h$ and $n$ denote stockholders and non-stockholders respectively; $c$ and $l$ denote consumption and labor supply, respectively. For the parametrizations I consider below, the risk aversion parameter for static wealth gambles will be proportional to $\alpha^{i}$, and the EIS will be inversely proportional to $\rho^{i}$, although the precise relationship will also depend on the choice of $u$. As indicated by the superscripts, the two types are allowed to differ in their preference parameters.

It should be emphasized that the choice of recursive preferences is made mainly for clarity: by disentangling risk aversion from the elasticity of intertemporal substitution, these preferences allow us to examine the impact of heterogeneity in the EIS on asset prices without generating corresponding differences in risk aversion that could confound the inference. ${ }^{2,3}$

The Firm. There is an aggregate firm producing a single consumption good using capital $\left(K_{t}\right)$ and labor $\left(L_{t}\right)$ inputs according to a Cobb-Douglas technology: $Y_{t}=Z_{t} K_{t}^{\theta} L_{t}^{1-\theta}$, where $\theta \in(0,1)$ is the factor share parameter. The technology level evolves according to:

$$
\log \left(Z_{t+1}\right)=\phi \log \left(Z_{t}\right)+\varepsilon_{t+1}, \quad \varepsilon \stackrel{i i d}{\sim} N\left(0, \sigma_{\varepsilon}^{2}\right)
$$

The firm's managers maximize the value of the firm, which equals the value of the fu-

\footnotetext{
${ }^{2}$ This expositional advantage notwithstanding, the ability to calibrate risk aversion and EIS separately is not essential for the main substantive results of the paper. This can be seen by comparing the results reported here to the working paper version (Guvenen (2006)), which uses CRRA preferences.

${ }^{3}$ Habit preferences also break the reciprocal relation between the RRA and EIS parameters. However, as is well-known, these preferences can generate a high equity premium even in a simple RBC model with inelastic labor supply and capital adjustment costs (Jermann (1998)). Therefore, using habit in the present model would confound the mechanisms created by habit with those studied here (e.g., resulting from limited participation). Having said that, given the popularity of habit preferences in the recent business cycle research (see, e.g., Christiano, Eichenbaum, and Evans (2005)), future work should explore the implications of a model that combines habit formation with limited stock market participation.
} 
ture dividend stream generated by the firm, $\left\{D_{t+j}\right\}_{j=1}^{\infty}$, discounted by the marginal rate of substitution process of firm owners, $\left\{\beta^{j} \Lambda_{t, t+j}\right\}_{j=1}^{\infty}$. Specifically, the firm's problem is:

$$
P_{t}^{s}=\max _{\left\{I_{t+j}, L_{t+j}\right\}} E_{t}\left[\sum_{j=1}^{\infty} \beta^{j} \Lambda_{t, t+j} D_{t+j}\right]
$$

subject to the law of motion for capital, which features "adjustment costs" in investment:

$$
K_{t+1}=(1-\delta) K_{t}+\Phi\left(\frac{I_{t}}{K_{t}}\right) K_{t}
$$

$P_{t}^{s}$ is the ex-dividend value of the firm, and I normalize the number of shares outstanding to unity (for convenience) so that $P_{t}^{s}$ is also the stock price. The adjustment cost function $\Phi(\cdot)$ is concave in investment, which captures the difficulty of quickly changing the level of capital installed in the firm.

Every period the firm sells one-period bonds, at price $P_{t}^{f}$, to finance part of its investment. The total supply of these bonds is constant over time and equals a fraction, $\chi$, of the average capital stock owned by the firm (as in Jermann (1998), Danthine and Donaldson (2002)). As a result, the firm makes net interest payments in each period in the amount of $\left(1-P_{t}^{f}\right) \chi \bar{K}$ to bond owners. ${ }^{4}$ An equity share in this firm entitles its owner to the entire stream of future dividends, which is given by the profits net of wages, investment, and interest payments: $D_{t}=Z_{t} K_{t}^{\theta} L_{t}^{1-\theta}-W_{t} L_{t}-I_{t}-\left(1-P_{t}^{f}\right) \chi \bar{K}$.

Financial Markets. In this economy, the firm's equity shares (stocks) and one-period bonds issued by the firm are traded. The difference between the two groups is in their investment opportunity sets: the "non-stockholders" can freely trade the risk-free bond, but they are restricted from participating in the stock market. The "stockholders," on the other hand, have access to both markets and hence are the sole capital owners in the economy. Finally, I impose portfolio constraints as a convenient way to prevent Ponzi schemes.

Individuals' Dynamic Problem and the Equilibrium. In a given period, the portfolio of each group can be expressed in terms of the beginning-of-period capital stock, $K$, the aggregate bond holdings of non-stockholders after production, $B$, and the technology level,

\footnotetext{
${ }^{4}$ The introduction of corporate debt into this framework allows me to model bonds as a positive net supply asset, which is more realistic. However, the Modigliani-Miller theorem holds in this framework in the sense that stockholders are able to fully undo the effect of leverage in their portfolio. Therefore, the existence of leverage has no effect on quantity allocations, which I have verified by solving the model without leverage.
} 
$Z$. Let $\Upsilon$ denote the aggregate state vector $(K, B, Z)$. The dynamic programming problem of a stockholder can be expressed as follows:

$$
V^{h}(\omega ; \mathbf{\Upsilon})=\max _{c, l, b^{\prime}, s^{\prime}}\left[(1-\beta) u(c, 1-l)+\beta\left(E\left[V^{h}\left(\omega^{\prime} ; \mathbf{\Upsilon}^{\prime}\right) \mid Z\right]^{1-\alpha^{i}}\right)^{\frac{1-\rho^{i}}{1-\alpha^{i}}}\right]^{\frac{1}{1-\rho^{i}}}
$$

s.t.

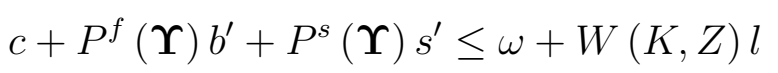

$$
\begin{aligned}
& \omega^{\prime}=b^{\prime}+s^{\prime}\left(P^{s}\left(\Upsilon^{\prime}\right)+D\left(\Upsilon^{\prime}\right)\right) \\
& K^{\prime}=\Gamma_{K}(\Upsilon), B^{\prime}=\Gamma_{B}(\Upsilon) \\
& b^{\prime} \geq \underline{B} \text {, }
\end{aligned}
$$

where $\omega$ denotes financial wealth; $b^{\prime}$ and $s^{\prime}$ are individual bond and stock holdings, respectively; $\Gamma_{K}$ and $\Gamma_{B}$ denote the laws of motion for the wealth distribution which are determined in equilibrium; and $P^{f}$ is the equilibrium bond pricing function. The problem of a non-stockholder can be written as above with $s^{\prime} \equiv 0$, and the superscript $h$ replaced with $n$. Finally, the stock return and the risk-free rate are defined as usual: $R^{s}=\left(P^{s \prime}+D^{\prime}\right) / P^{s}-1$ and $R^{f}=1 / P^{f}-1$, and the equity premium is denoted by $R^{e p} \equiv R^{s}-R^{f}$.

A stationary recursive competitive equilibrium for this economy is given by a pair of

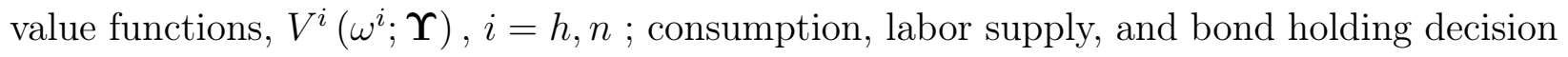

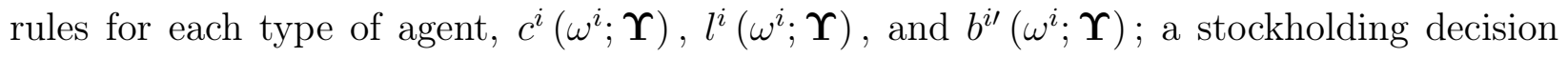

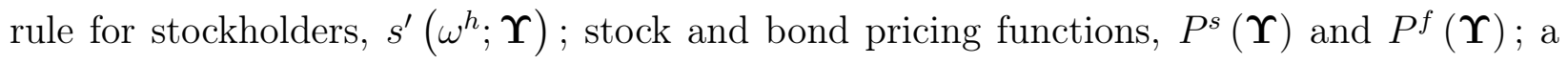
competitive wage function, $W(K, Z)$; an investment function for the firm, $I(\boldsymbol{\Upsilon})$; laws of motion for aggregate capital and the aggregate bond holdings of non-stockholders, $\Gamma_{K}(\Upsilon)$,

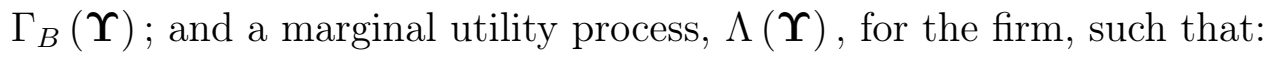

1) Given the pricing functions and the laws of motion, the value function and decision rules of each agent solve that agent's dynamic problem.

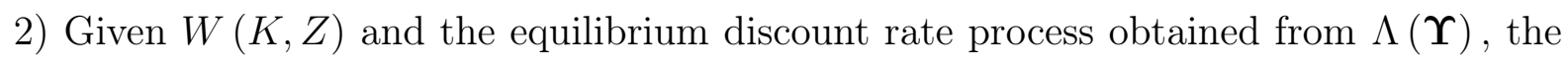

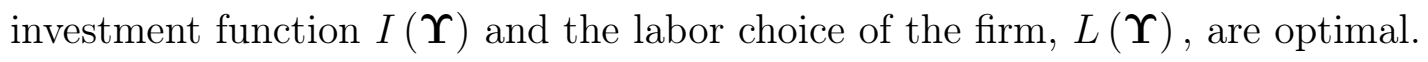

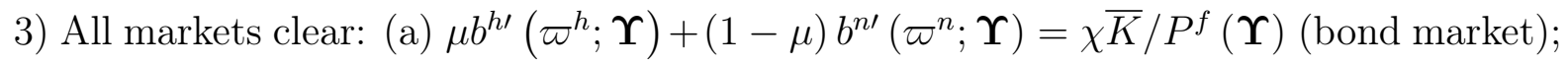

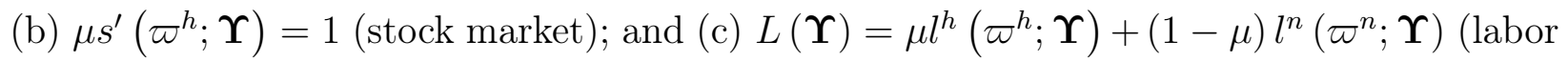
market), where $\varpi^{i}$ denotes the wealth of each type of agent in state $\Upsilon$ in equilibrium.

4) Aggregate laws of motion are consistent with individual behavior: $K^{\prime}=(1-\delta) K+$

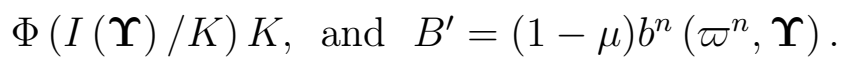

5) There exists an invariant probability measure $\mathbf{P}$ defined over the ergodic set of equilibrium distributions. 


\section{Quantitative Analysis}

The solution to the recursive competitive equilibrium is obtained using numerical methods. In addition to the well-known challenges associated with solving incomplete markets asset pricing models (cf., Krusell and Smith (1997) and Storesletten et al (2007)), the present model is further complicated by the presence of (i) capital adjustment costs, (ii) Epstein-Zin preferences, and (iii) leverage. These features raise a number of issues that we now discuss.

First, because markets are incomplete, one cannot solve for allocations first and then obtain prices as is typically done in representative agent models. Instead, allocations and pricing functions must be solved for simultaneously. Second, the three features mentioned above introduce important non-linearities into equilibrium functions, making it essential to start the algorithm with good initial guesses and update them very slowly. Third, asset prices are well-known to be more sensitive to approximation errors (much more so than quantity allocations). Furthermore, some key variables in the model exhibit significant volatility and are, therefore, not confined to narrow regions of the state space, so the accuracy of local (e.g., log-linear, etc.) approximations is not always easy to ensure. So, instead, I approximate the equilibrium functions over the entire state space using multi-dimensional cubic splines and check that equilibrium conditions (1-5 above) are satisfied at all grid points. Finally, the wealth distribution (which is a relevant state vector in this model) is not approximated by moments as done by Krusell and Smith (1997), but instead its evolution is tracked exactly via the functions $\Gamma_{K}$ and $\Gamma_{B}$. Of course, this is only feasible here because there are two types of agents, so the wealth distribution has only two dimensions. Overall, the algorithm I use trades off speed for precision, and is therefore not very fast but delivers accurate results.

I now provide an outline of the algorithm for the CONS model, which contains all the essential components. A supplemental computational appendix contains further details.

Step 0. Initialization. Choose appropriate grids for $\omega^{h}, \omega^{n}$ (each agent's wealth holdings) and $\Upsilon=(K, B, Z)$. Off-grid values for all functions are obtained by cubic spline interpolation. Initial guesses for equilibrium functions are obtained by solving a simplified version of the model with no adjustment costs $(\xi=\infty)$, no leverage $(\chi=0)$, and with CRRA utility $(\alpha=\rho)$. The algorithm for this simplified model is essentially the same as steps $1-5$ below (with no need for step 2-c because $P^{s} \equiv K$ ), but is much more stable. Let superscript $j$ index the iteration number. Set $j=1$ and start the iteration:

Step 1. Solve each agent's dynamic problem (defined by equations (4)-(8)). These are standard Bellman equations and are solved via value function iteration. The fact that 
preferences are of the Epstein-Zin form poses no additional difficulty in this step-in fact, it makes it easier in certain ways. More on this in the appendix.

Step 2. Update equilibrium functions: $\Lambda^{j-1}, I^{j-1}, D^{j-1}, P^{s, j-1}, \Gamma_{K}^{j}$.

(a) Use $c^{h, j}(\omega ; \Upsilon)$ and $V^{h, j}(\omega ; \Upsilon)$ obtained in step 1 to construct the stochastic discount factor $\Lambda^{j}\left(\boldsymbol{\Upsilon}, Z^{\prime}\right)$. Using $\Lambda^{j}$ solve the firm's problem ((2) and (3)) to obtain $I^{j}(\Upsilon)$.

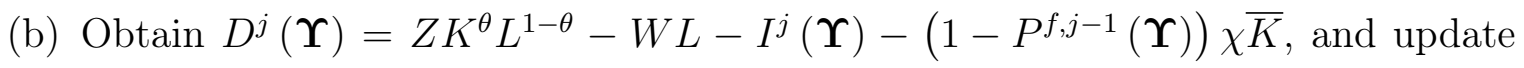
$\Gamma_{K}^{j}(\mathbf{\Upsilon}): K^{\prime}=(1-\delta) K+\Phi\left(I^{j}(\mathbf{\Upsilon}) / K\right) K$.

(c) Define the temporary variable $\widetilde{P}^{0}(\boldsymbol{\Upsilon}) \equiv P^{s, j-1}(\boldsymbol{\Upsilon})$. Now iterate for $m=1, \ldots, M$ :

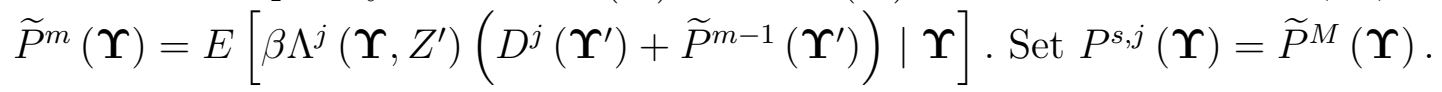

Step 3: Update the bond pricing function, $P^{f, j-1}$. The method here follows Krusell and Smith (1997) closely. First, solve:

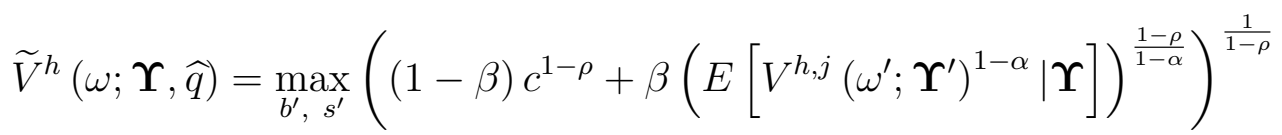

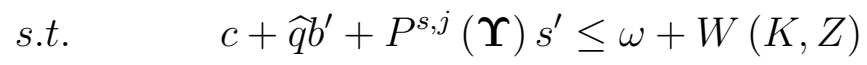

and equations (6)-(8) (and with $s^{\prime} \equiv 0$ for the non-stockholder). The only difference between this problem and the individual's original Bellman equation is that here the individual views the current period bond price as some arbitrary parameter $\widehat{q}$, which is not

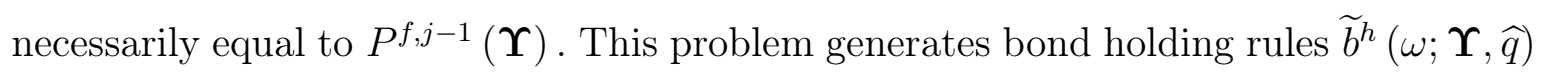
and $\widetilde{b}^{n}(\omega ; \Upsilon, \widehat{q})$ which explicitly depend on $\widehat{q}$. Then, at each grid point, search over values of $\widehat{q}$ to find $q^{*}$ such that the bond market clears, i.e., excess demand is less than

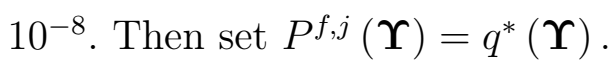

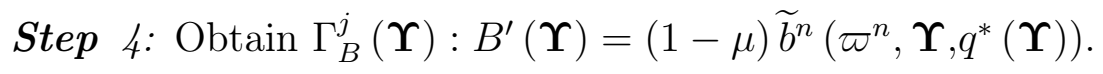

Step 5: Iterate on Steps 1 to 4 until convergence. I require maximum percentage discrepancy (across all points in the state space) between consecutive iterations to be less than $10^{-6}$ for $P^{f}, 10^{-4}$ for $P^{s}$, and $10^{-6}$ for aggregate laws of motion. Further tightening these convergence criteria has no noticeable effect.

As further described in the appendix, additional checks are conducted to ensure the accuracy of the solution. For example, one should also test if the stock market clears at all state points, which is not explicitly imposed by the algorithm above. It indeed does: the maximum $\left|\mu s^{\prime}\left(\varpi^{h} ; \Upsilon\right)-1\right|<10^{-5}$. Another useful check is to see if increasing the number of grid 
points changes the results: doubling the number of points in $\omega$ and $K$ directions and tripling in the $B$ direction (simultaneously) had no noticeable effect on the statistics studied in the paper. Further details are provided in the supplementary computational appendix.

\subsection{Baseline Parametrization}

A model period corresponds to one month of calendar time to approximate the frequent trading in financial markets. Because asset pricing statistics are typically reported at annual frequencies and macroeconomic statistics are reported at quarterly frequencies, I aggregate financial variables and quantities to their respective reporting frequencies to calculate the relevant statistics as explained below. Table I summarizes the baseline parameter choices.

The capital share parameter, $\theta$, is set to 0.3 . The functional form for $\Phi$ is specified as $a_{1}\left(I_{t} / K_{t}\right)^{1-1 / \xi}+a_{2}$, as in Jermann (1998), where $a_{1}$ and $a_{2}$ are constants chosen such that the steady state level of capital is invariant to $\xi$. The curvature parameter $\xi$ determines the severity of adjustment costs. As $\xi$ approaches infinity, $\Phi$ becomes linear, and investment is converted into capital one for one (frictionless economy limit). At the other extreme, as $\xi$ approaches zero, $\Phi$ becomes a constant function, and the capital stock remains constant regardless of the investment level (exchange economy limit). I set $\xi=0.40$, which is broadly consistent with the values reported in the empirical literature (see Christiano and Fisher (1998) for a survey of existing estimates). Because there is also a fair amount of disagreement about the correct value of $\xi$, in Section 6.2 I also conduct sensitivity analysis with respect to this parameter. The calibration of the capital accumulation equation is completed by setting $\delta$ to 0.0066 , implying a quarterly depreciation rate of $2 \%$. As for the technology shock, I match the first order autocorrelation of 0.95 of the Solow residuals at quarterly frequencies by setting $\phi=0.976$ at monthly frequency. I discretize the $\operatorname{AR}(1)$ process for $Z_{t}$ using a 15-state Markov process. The innovation standard deviation, $\sigma_{\varepsilon}$, is set later below.

Given the absence of idiosyncratic shocks in the present model, it does not seem realistic for borrowing constraints to bind frequently for entire groups of population. Therefore, in the baseline case I calibrate these constraints to be quite loose-equal to 6 months of labor income for both types of agents - which almost never bind in the simulations. ${ }^{5}$ As for the calibration of the leverage ratio, Masulis (1988, Table 1.3) reports that the leverage ratio (debt/book value) of US firms has varied between $13 \%$ and 44\% from 1929 to 1986 . With my calibration, the leverage ratio in the model is set to $15 \%$ of the average equity value and

\footnotetext{
${ }^{5}$ In the supplementary appendix, I show that if constraints were tight enough to bind frequently, if anything this raises the equity premium.
} 
Table I: Baseline Parametrization

\begin{tabular}{llr}
\hline \hline Parameter & & Value \\
\hline \multicolumn{3}{c}{ Parameters calibrated outside the model } \\
\hline$\beta^{*}$ & Time discount rate & 0.99 \\
$1 / \rho^{h}$ & EIS of stockholders & 0.3 \\
$1 / \rho^{n}$ & EIS of non-stockholders & 0.1 \\
$\mu$ & Participation rate & 0.2 \\
$\phi^{*}$ & Persistence of aggregate shock & 0.95 \\
$\theta$ & Capital share & 0.30 \\
$\xi$ & Adjustment cost coefficient & 0.40 \\
$\delta^{*}$ & Depreciation rate & 0.02 \\
$\underline{B}$ & Borrowing limit & $6 \bar{W}$ \\
$\chi$ & Leverage ratio & 0.15 \\
\hline \multicolumn{3}{c}{ Parameters calibrated inside the model (to match targets) } \\
\hline$\sigma_{\varepsilon}^{*}$ & Standard deviation of shock (\%) & $1.5 / 1.5 / 1.1$ \\
$\alpha^{h}=\alpha^{n}$ & Relative risk aversion
\end{tabular}

"*" indicates that the reported value refers to the implied quarterly value for a parameter that is calibrated to monthly frequency. $\bar{W}$ is the average monthly wage rate in the economy. The last two parameters are chosen to (1) match the standard deviation of H-P filtered output in quarterly data (1.89\%) and (2) generate an annual Sharpe ratio of 0.25 . The standard deviation values refer to CONS/CD/GHH models, respectively.

fluctuates between $11 \%$ and $32 \%$. Moreover, this calibration also ensures that the firm is always able to pay its interest obligations, so the corporate bond is default-free.

Participation Rates. The model assumes a constant participation rate in the stock market, which seems to be a reasonable approximation for the period before the 1990s when the participation rate was either stable or increasing gradually (Poterba and Samwick (1995, Table 7)). In contrast, during the 1990s participation has increased substantially: from 1989 to 2002 the number of households who owned stocks increased by $74 \%$, and by 2002 half of the US households had become stock owners (Investment Company Institute (2002)). Modeling the participation boom in this later period would require going beyond the stationary structure of the present model, so instead, I exclude this later period (1992-) both when calibrating the participation rate and when comparing the model to the data. I set the participation rate in the model, $\mu$, to $20 \%$, roughly corresponding to the average rate from 1962 to 1992 (a period during which participation data is available). Note that even during times when participation was higher, households in the top $20 \%$ have consistently owned more than $98 \%$ of stocks (Poterba and Samwick (1995, Table 9)). 
Utility Functions. I consider three different specifications for the period utility function. First, to provide a simple and well-known benchmark, I begin with the case where labor supply is inelastic (i.e., leisure is not valued) and assume that the period utility function is of the standard power form: $u(c, 1-l)=c^{1-\rho^{i}}$. This is a useful benchmark that allows a direct comparison to the existing literature where inelastic labor supply is the most common assumption. In addition, this case allows us to illustrate the key mechanisms resulting from limited participation in their simplest form. To distinguish between different versions of the model, I will refer to this case as the "CONS model."

The remaining two specifications feature valued leisure for a full-blown quantitative analysis. The first one features a Cobb-Douglas function (hereafter, the "CD model") commonly used in macroeconomic analysis: $u(c, 1-l)=\left(c^{\gamma}(1-l)^{1-\gamma}\right)^{1-\rho^{i}}$. However, one restrictive property of this functional form is that $\rho^{i}$ and $\gamma$ jointly pin down the EIS, the fraction of time devoted to market work, and the Frisch labor supply elasticity. In other words, choosing the two parameters to match the first two empirical magnitudes automatically pins down the Frisch elasticity, which is a serious restriction given that we are interested in constructing a model that allows to study macro quantities and asset prices jointly. To overcome this difficulty I use a third utility function: $u(c, 1-l)=\left(c-\psi \frac{l^{1+\gamma}}{1+\gamma}\right)^{1-\rho^{i}}$, introduced by Greenwood et al. (1988, hereafter the "GHH model"). This specification has three distinct parameters that can be chosen to separately target the three parameters mentioned above. This feature will be useful in the analysis that follows.

Preference Parameters. There is a large body of empirical work documenting heterogeneity in the EIS across the population (see Guvenen (2006) for a more comprehensive review of the empirical evidence). These studies find that, by and large, non-stockholders (and the poor in general) have an elasticity of substitution that is very low-close to zerowhile stockholders (and the wealthy in general) have an EIS that is higher. For example, Blundell et al. (1994) estimate that households in the top income quintile have an EIS that is three times that of households in the bottom quintile of the distribution. Similarly, Barsky et al. (1997) estimate the distribution of the EIS parameter in the population and find the average to be below 0.2 , but also find the highest percentiles to be exceeding unit elasticity.

One theoretical explanation for this observed heterogeneity is provided by Browning and Crossley (2000). They start with a model of choice where agents consume several goods with different income elasticities. Because the budget share of luxuries rises with wealth, the aggregate consumption bundle of wealthy individuals have more goods with high income 
elasticities than that of poor individuals. Browning and Crossley (2000) prove that this observation also implies that luxuries are easier to postpone than necessities, and consequently, that the EIS (with respect to total consumption) increases with wealth. Since stockholders are substantially wealthier than non-stockholders, this also implies heterogeneity in the EIS across these two groups as found in these studies. To broadly capture the empirical evidence described above, I set the EIS of non-stockholders to 0.1 and assume an EIS that is three times higher (0.3) for stockholders (in all versions of the model). ${ }^{6}$ Finally, I set $\beta$ equal to 0.9966 (monthly) so as to match the US capital-output ratio of 2.5 in annual data.

With Cobb-Douglas preferences, there is only one additional parameter, $\gamma$, which is chosen to match the average time devoted to market activities ( 0.36 of discretionary time). I continue to keep the EIS values of both groups as above. However, as noted above, $\gamma$ and $\rho^{i}$ also determine the Frisch labor supply elasticity, which means that assuming heterogeneity in the EIS also implies unintended heterogeneity in the Frisch elasticity: 1.35 for stockholders and 0.69 for non-stockholders. Although such heterogeneity is difficult to justify with any empirical evidence I am aware of, there seems to be no practical way to get around this problem with $\mathrm{CD}$ preferences. I will return back to this caveat later.

The GHH specification provides more flexibility, with two additional parameters. The Frisch elasticity is now equal to $1 / \gamma$ for both types of agents, which I set equal to 1 . This value is consistent with the estimates reported in Kimball and Shapiro (2003). However, there is a fair degree of disagreement in the literature about the correct value of this parameter, so I also discuss below the effect of different values for $\gamma$ on the results. The average hours worked is given by: $\bar{L}=(\bar{W}(\kappa) /((1+\gamma) \kappa))^{1 / \gamma}$, where $\bar{W}(\kappa)$ is the average wage rate in the economy whose dependence on $\kappa$ is made explicit. For a target value of $\bar{L}=0.36$, this equation is solved to obtain the required value of $\kappa$.

The existing empirical evidence on the risk aversion parameter is much less precise than one would like. Moreover, the limited evidence available pertains to the population average,

\footnotetext{
${ }^{6}$ Although in this paper I do not explicitly model the source of the heterogeneity in the EIS (so as not to add another layer of complexity), one way to do this would be by assuming non-homothetic preferences following Browning and Crossley's analysis. Specifically, suppose that both agents have identical utility functions featuring "benchmark consumption levels": $u_{t}^{i}=\left(c_{t}^{i}-a \bar{C}_{t}\right)^{1-\rho} /(1-\rho)$, where $\bar{C}_{t}$ is aggregate consumption. With this specification, the EIS is rising with the consumption (and, therefore, the wealth) of an individual. But, furthermore, wealth inequality in this framework is mainly due to limited participation and is quite robust to changes in the curvature of the utility of both agents (see Guvenen (2006) for a detailed analysis of this point). Therefore, with these preferences stockholders continue to be much wealthier and, consequently, consume more than non-stockholders. By choosing $\rho$ and $a$ appropriately, one can generate the same EIS values, assumed (exogenously) in the present paper. The supplemental appendix presents the details of such a calibration that broadly generates the same asset pricing results as in the CONS model.
} 
whereas what will matter for asset prices in this framework is the risk aversion of stockholders, who constitute only a small fraction of the population, making those average figures even less relevant. Therefore, I calibrate the risk aversion of stockholders indirectly, i.e., by matching the model to some empirical targets. (I also conduct a sensitivity analysis in Section 6.2.)

Specifically, I first consider the CONS model. I choose the two parameters that are free at this point $\left(\alpha^{h}, \sigma_{\varepsilon}\right)$ to match two empirical targets: (1) the volatility of H-P filtered quarterly output (1.89\%) and (2) an annual Sharpe ratio of 0.25 . I then set the risk aversion of nonstockholders equal to the same value. My target value for the Sharpe ratio is somewhat lower than the 0.32 figure in the US data (Table II). This is because forcing the model to explain the full magnitude of the risk premium is likely to come at the expense of poor performance in other areas, such as macro behavior or asset price dynamics, which I am also interested in analyzing. The present choice is intended to balance these different considerations.

For practical considerations, I restrict the parameter search to integer values in the $\alpha^{h}$ direction (from 2 to 10 ) and consider 0.1 increments in the $\sigma_{\varepsilon}$ direction (from $0.05 \%$ to $2 \%$ ). I minimize an equally weighted quadratic objective written in the percent deviation from each empirical target. The minimum is obtained for $\sigma_{\varepsilon}=1.5 \%$ (quarterly standard deviation) for the CONS model with $\alpha^{h}=6$. For the CD and GHH models, I keep the risk aversion parameter at this value and choose $\sigma_{\varepsilon}$ in each case to match output volatility. The resulting values are $\sigma_{\varepsilon}=1.5 \%$ in the $\mathrm{CD}$ model and $\sigma_{\varepsilon}=1.1 \%$ in the GHH model. ${ }^{7}$

These values of the innovation standard deviation are close to the values used by BCF, Danthine and Donaldson (2002), and Storesletten et al. (2007) in a context similar to ours. ${ }^{8}$ Nevertheless, these figures are quite high compared to the direct estimate of the volatility of Solow residuals for the post war period, which is about $0.7 \%$. This suggests that it may be more appropriate to interpret the exogenous driving source in this class of models as encompassing more than just technology shocks (such as fiscal policy shocks, among others).

\section{Model Results: Asset Prices}

\subsection{The Unconditional Moments of Asset Prices}

\footnotetext{
${ }^{7}$ These volatility figures are helped a bit by the choice of a monthly decision frequency and time aggregation of the resulting simulated data. If, instead, the model were solved at quarterly frequency, the values of $\sigma_{\varepsilon}$ necessary to match the same targets would be 10-15\% higher depending on specification.

${ }^{8} \mathrm{BCF}$ use permanent shocks with $\sigma_{\varepsilon}=1.8 \%$ per quarter, Storesletten et al. (2007) also use permanent shocks with $\sigma_{\varepsilon}=3.3 \%$ per year. Danthine and Donaldson (2002) use a two-state Markov process with persistence of 0.97 and a $\sigma_{\varepsilon}=5.6 \%$ per quarter.
} 
Table II: Unconditional Moments of Asset Returns, Model with Inelastic Labor Supply

\begin{tabular}{|c|c|c|c|c|c|}
\hline \multirow{3}{*}{$\begin{array}{l}\alpha^{h}, \alpha^{n} \\
1 / \rho^{h}, 1 / \rho^{n}\end{array}$} & \multirow[t]{2}{*}{ US Data } & \multicolumn{4}{|c|}{$\overline{\text { CONS Model }}$} \\
\hline & & $6 / 6$ & $6 / 6$ & $6 / 6$ & $6 / \mathbf{1 2}$ \\
\hline & & $0.3 / 0.1$ & $0.3 / \mathbf{0 . 3}$ & $0.1 / 0.1$ & $0.3 / 0.1$ \\
\hline & \multicolumn{5}{|c|}{ A. Stock and Bond Returns } \\
\hline$E\left(R^{e p}\right)$ & $6.17(1.99)$ & 5.46 & 2.44 & 7.65 & 5.52 \\
\hline$\sigma\left(R^{e p}\right)$ & $19.4(1.41)$ & 21.9 & 15.3 & 27.2 & 22.0 \\
\hline$\sigma\left(R^{s}\right)$ & $19.3(1.38)$ & 20.6 & 14.7 & 27.0 & 20.8 \\
\hline$E\left(R^{e p}\right) / \sigma\left(R^{e p}\right)$ & $0.32(0.11)$ & $0.25^{a}$ & 0.16 & 0.28 & 0.25 \\
\hline$E\left(R^{f}\right)$ & $1.94(0.54)$ & 1.31 & 3.20 & 0.24 & 1.35 \\
\hline \multirow[t]{2}{*}{$\sigma\left(R^{f}\right)$} & $5.44(0.62)$ & 6.65 & 4.55 & 8.52 & 6.71 \\
\hline & \multicolumn{5}{|c|}{ B. Price-Dividend Ratio } \\
\hline$E\left(P^{s} / D\right)$ & $22.1(0.58)$ & 27.2 & 25.9 & 29.5 & 27.1 \\
\hline$\sigma\left(\log \left(P^{s} / D\right)\right)$ & $26.3(1.67)$ & 26.6 & 13.8 & 38.7 & 26.9 \\
\hline \multirow[t]{2}{*}{$\sigma(\Delta \log D)$} & $13.4(0.94)$ & 19.1 & 14.0 & 24.2 & 19.1 \\
\hline & \multicolumn{5}{|c|}{ C. Consumption Growth Volatility } \\
\hline$\frac{\sigma\left(\Delta \log c^{h}\right)}{\sigma\left(\Delta \log c^{n}\right)}$ & $>1.5-2.0^{b}$ & 2.42 & 0.78 & 1.12 & 2.44 \\
\hline
\end{tabular}

\begin{abstract}
${ }^{a}$ The Sharpe ratio of 0.25 is one of the two empirical targets in the calibration. All statistics are reported in annualized percentages. Annual returns are calculated by summing up log monthly returns. The numbers in parenthesis in the first column are the standard errors of the statistics to reflect the sampling variability in the US data.

${ }^{b}$ The value reported here represents an approximate lower bound for this ratio based on the empirical evidence discussed in Section 5.1.
\end{abstract}

I begin by discussing the unconditional moments of stock and bond returns, and then turn to the conditional moments in the next section. Table II displays the statistics from the simulated model along with their empirical counterparts computed from the historical US data covering the period $1890-1991 .^{9}$ I first examine the inelastic labor supply case shown in column 2. This case provides a useful benchmark, both because it is the most common case studied in the literature and because it allows one understand the key mechanisms generated by limited participation without the added complexity of labor supply choice.

The Equity Premium. As shown in the second column of Table II, in the calibrated model the target Sharpe ratio of 0.25 is attained with a moderately high risk aversion of 6. Clearly, a given Sharpe ratio can be generated by many different combinations of equity

\footnotetext{
${ }^{9}$ The data are taken from Campbell (1999). The stock return and the risk-free rate are calculated from Standard and Poor's 500 index and the six-month commercial paper rate (bought in January and rolled over in July), respectively. All returns are real and are obtained by deflating nominal returns with the consumption deflator series available in the same data set.
} 
premium and volatility, so matching this target does not say anything about the numerator and the denominator. The corresponding equity premium is $5.45 \%$, which is slightly lower than the historical figure of $6.2 \%$. The volatility of the equity premium is $21.9 \%$ compared to $19.4 \%$ in the data. Therefore, the model generates an equity premium with mean and volatility that are in the right ballpark compared to the data.

The Mechanism. The high equity premium is generated by a general equilibrium mechanism that amplifies stockholders' consumption growth volatility and does so in a procyclical fashion, causing them to demand a high equity premium. Specifically, the mechanism results from the interaction of three features of the model, which reinforce each other. First, limited participation creates an asymmetry in consumption smoothing opportunities: facing persistent (aggregate) labor income shocks, non-stockholders have to exclusively rely on the bond market, whereas stockholders have another margin - they can also adjust their capital holdings. Second, because of their low EIS, non-stockholders have a stronger desire for a smooth consumption process compared to stockholders. The combination of these two effects imply that non-stockholders need the bond market much more than stockholders. Third, and importantly, the bond market is not a very effective device for consumption smoothing in the face of aggregate risk, because it merely reallocates the risk rather than reducing it, as would be the case if shocks were idiosyncratic. As a result, non-stockholders' desire for smooth consumption is satisfied via trade in the bond market, at the expense of higher volatility in stockholders' consumption. Moreover, since these large fluctuations in stockholders' consumption are procyclical, they are reluctant to own the shares of the aggregate firm that performs well in booms and poorly in recessions. Therefore, they demand a high equity premium. In Section 5, I quantify the role of this mechanism and contrast it with earlier models of limited participation, such as Saito (1995) and Basak and Cuoco (1998).

The Risk-Free Rate. Turning to the risk-free rate, the mean is $1.3 \%$, which compares well to the low average interest rate of $1.9 \%$ in the data. It is important to note that the low risk-free rate is helped by the fact that the model abstracts from long-run growth and preferences are of the Epstein-Zin form. To see this, consider the following expression for the $\log$ risk-free rate, which holds as a fairly good approximation: ${ }^{10}$

$$
r_{t}^{f} \approx-\ln \beta+\rho^{h} E_{t}\left(\Delta \log c_{t+1}^{h}\right)+\kappa,
$$

\footnotetext{
${ }^{10}$ For an exact derivation of this expression, human wealth would need to be tradeable. Although this is not the case in the present model, the equation holds fairly well and provides a useful approximation.
} 
where $\kappa$ contains terms that involve the volatility of consumption and wealth, which turns out to be secondary for the present discussion.

With secular growth, the consumption growth term on the right-hand side would be non-zero - unlike in the present model-pushing the average risk-free rate up. For example, taking an annual growth rate of $1.5 \%$, and setting $\rho^{h}=3.33$ as calibrated above, would imply $r_{t}^{f}=5.85 \%$. As is well-known, this "risk-free rate puzzle" is even more severe with CRRA utility, because in this case it would be the risk aversion parameter that would appear in front of the second term, which is $\alpha^{h}=6$ in this case, implying $r_{t}^{f}=10.2 \%$. This discussion reiterates the well-known point that models with CRRA utility functions and long-run growth that match the equity premium typically imply a high average interest rate. Epstein-Zin preferences mitigate this problem if one assumes an EIS that is higher than the reciprocal of the risk aversion parameter, as is the case here.

Another well-documented feature of the interest rate-and as it turns out, a challenging one to explain - is its low volatility. The standard deviation is $5.44 \%$ in the historical sample, although different time periods (such as the post war sample) can yield values as low as $2 \%$ per year (see, e.g., Campbell 1999 for a discussion). The corresponding figure is $6.65 \%$ in the model (and further falls to $4.1 \%$ with endogenous labor supply below). Although this figure is higher than the empirical values, the low volatility of the interest rate has turned out to be quite difficult to generate, especially in macro-asset pricing models. For example, as I report in Table III, this volatility is $24.6 \%$ in BCF and $10.6 \%$ in Danthine and Donaldson (2002); it is $11.5 \%$ in Jermann (1998) (not reported). Thus, the present model provides a step in the right direction. So, what explains the relatively low variability of interest rates in the model?

To understand the mechanism, consider the bond market diagram in Figure 1. The left panel depicts the case of a representative agent with a low EIS, which is a feature common to the models mentioned above. For example, both the endogenous and the external habit models imply a low EIS (despite differing in their risk aversion implications). With a low EIS, however, the interaction of the resulting inelastic (steep) bond demand curve with a bond supply that is perfectly inelastic at zero (because of the representative-agent assumption) means that even small shifts in the demand curve - due to labor income shocks and the consequent change in the demand for savings - generate large movements in the bond price, and hence, in the risk-free rate.

In the present model, the mechanism is different. First, for the following discussion it is convenient to label non-stockholders' bond decision rule as the "bond demand" and the 
Figure 1: Determination of Bond Price Volatility
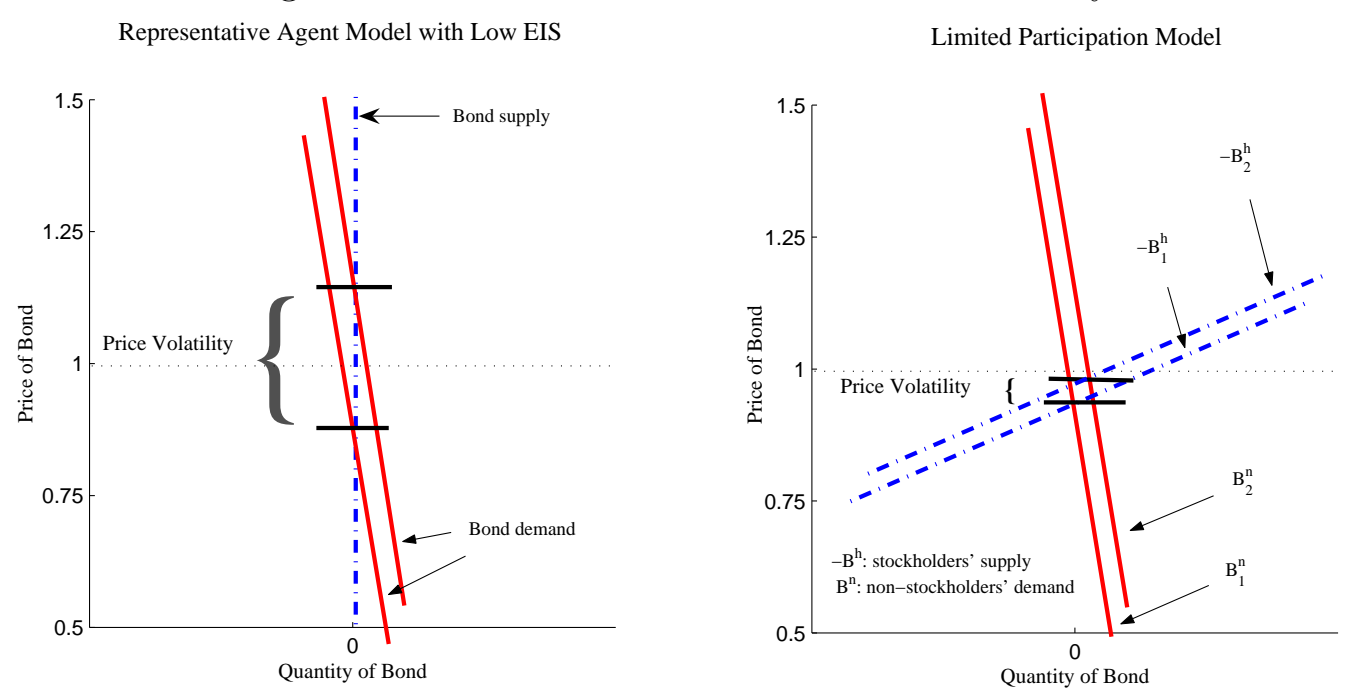

negative of stockholders' bond decision rule as the "bond supply." Now, notice that the majority - 80\% - of the population (non-stockholders) have a very low EIS as before, implying very inelastic bond demand (right panel). Turning to bond supply, the key difference here is that it is not inelastic at all. In fact, the stockholders' supply curve is rather flat, both because of their higher EIS and because they have another asset - equity in the firm - that can act as a partial substitute for bond. As a result, a shift in the bond demand curve (resulting from fluctuations in non-stockholders' labor income) of similar magnitude as before now results in smaller fluctuations in the interest rate, and the rest is reflected in the variability of trade volume.

The Price-Dividend Ratio. The average price-dividend $(\mathrm{P} / \mathrm{D})$ ratio in the CONS model is 27.2 , which is about $20 \%$ higher than the average of 22.1 in the data. Its volatility is $26.6 \%$, which compares fairly well with the empirical figure (26.2\%). Finally, the volatility of dividend growth is $19.1 \%$, which is too volatile compared to the $13.4 \%$ figure in the US data. This high volatility is due to the leverage in the capital structure and is one of the dimensions that the labor supply choice will help with.

\subsection{The Role of Preference Heterogeneity}

One advantage of Epstein-Zin utility is that it allows me to easily examine the effects of heterogeneity in the EIS and risk aversion parameters on asset prices. I conduct three experiments reported in the last three columns of Table II. First (column 3), I keep all aspects of the baseline parametrization intact, but only increase non-stockholders' EIS from 
0.1 to 0.3 , which eliminates all preference heterogeneity from the model. With this change, the equity premium falls significantly, from $5.5 \%$ to $2.44 \%$, and its volatility falls from $21.9 \%$ to $15.3 \%$. More importantly, the price of risk falls from 0.25 to 0.16 . Moving down the column, the volatilities of all variables go down - by $30 \%$ to $50 \%$. This makes some variables, such as the $\mathrm{P} / \mathrm{D}$ ratio, too smooth compared to the data, while bringing some others closer to their empirical counterparts, such as the interest rate and dividend growth volatilities. Overall, these results show that the EIS of non-stockholders has a major impact on asset prices, perhaps most importantly on the equity premium and the Sharpe ratio, which are key statistics that this model seeks to explain.

Second, an alternative way to eliminate preference heterogeneity is by reducing the EIS of stockholders from 0.3 to 0.1 , which, as could be anticipated, has qualitatively the opposite effect (column 4). The equity premium now increases to $7.65 \%$, but the volatility is also higher at $27.2 \%$. As a result, the rise in the Sharpe ratio remains rather modest: it is 0.28 , up from 0.25. Finally, other volatilities, that of the interest rate, $\mathrm{P} / \mathrm{D}$ ratio, and dividend growth, are also significantly higher. Therefore, stockholders' EIS has a larger effect on volatilities, but a smaller one on the Sharpe ratio.

The two experiments above also reveal another role played by the EIS heterogeneity. As mentioned earlier, in the US data stockholders' consumption growth is more volatile than non-stockholders': $\sigma\left(\Delta \log c^{h}\right) / \sigma\left(\Delta \log c^{n}\right)>1.5-2.0$ (see section 5.1 for more details). The baseline CONS model is consistent with this empirical fact, generating a ratio of volatilities equal to 2.42 (panel $\mathrm{C}$ of Table II). However, if preference heterogeneity is eliminated, this ratio falls from 2.42 to 0.78 in column 3 and to 1.12 in column 4 . This is because stockholders have access to two separate assets that they can use to smooth consumption effectively, and absent preference heterogeneity they choose to do exactly that. (Notice that this result also explains why reducing stockholders' EIS in column 4 above had a small effect on the Sharpe ratio.)

To summarize the findings so far, the low EIS of non-stockholders plays an important role in generating a high Sharpe ratio, whereas lowering stockholders' EIS has a larger effect on asset price volatilities but only a small effect on the Sharpe ratio; furthermore, it creates a counterfactually low consumption growth volatility for this group. The baseline calibrationwith EIS heterogeneity - generates results consistent with both asset prices and the relative consumption volatility of the two groups.

Third, and finally, in the last column I examine the effect of non-stockholders' risk aversion, by doubling it to 12. Comparing column 5 to the baseline case in column 2 shows 
that this change has a minor effect, if at all, across the board. Surprisingly, doubling the risk aversion of $80 \%$ of the population has very little impact on the unconditional moments of asset prices. Loosely speaking, this is due to the fact that non-stockholders' only direct effect on asset prices is through the bond market, and their (precautionary) bond demand is largely determined by their EIS, but very little influenced by their risk aversion. ${ }^{11}$

\subsection{Asset Prices with Endogenous Labor Supply}

In the previous section I have found that the benchmark model with inelastic labor supply generated plausible behavior for the unconditional moments of stock and short-term bond returns. Nevertheless, labor supply choice is central for any serious macroeconomic analysis. Therefore, I now relax the inelastic labor supply assumption and consider the two utility functions - Cobb-Douglas and GHH_-described above.

Results. Table III reports the results (columns 2-4). To provide a comparison, the last two columns display the same set of statistics from two leading macro-asset pricing models proposed in the existing literature, namely BCF and Danthine and Donaldson (2002). The first paper features an endogenous labor-leisure choice, whereas the latter paper has inelastic labor and is more comparable to the model analyzed in the previous section.

With Cobb-Douglas utility (CD model, column 2), the first point to observe is the rather large fall in the equity premium, which is now $2.65 \%$ (compared to $5.5 \%$ with inelastic labor supply), accompanied by a smaller fall in the volatility (which is $15.4 \%$ compared to $21.9 \%$ before), resulting in a fall in the Sharpe ratio from 0.25 to 0.17. Moving down the column, notice that both the risk-free rate and dividend growth are less volatile than before, and now are closer to their respective empirical values. The $\mathrm{P} / \mathrm{D}$ ratio is also less volatile and is now too smooth compared to data. Overall, I view these results as a step backward compared to the model with inelastic labor supply.

I next turn to the GHH model in column 3, which delivers a more respectable equity premium level of $4.2 \%$, with a volatility of $17.5 \%$. The resulting Sharpe ratio is 0.24 , slightly lower than in the model with inelastic labor supply. Furthermore, the volatility of the riskfree rate is $4.1 \%$, which is lower than the model with inelastic labor supply (at 6.65\%). As noted earlier, this low volatility is also an important improvement of this model over earlier production economy models. As for the price-dividend ratio, the volatility is about $70 \%$ that

\footnotetext{
${ }^{11}$ Furthermore, in the supplementary appendix I also report the results on asset price dynamics for $\alpha^{n}=12$ and find that they are very similar to the case with $\alpha^{n}=6$.
} 
Table III: Unconditional Moments of Asset Returns, Model with Elastic Labor Supply

\begin{tabular}{|c|c|c|c|c|c|c|}
\hline \multirow[b]{2}{*}{ Endog. leisure? } & \multirow[t]{2}{*}{ US Data } & \multicolumn{3}{|c|}{ Model } & \multirow{2}{*}{$\begin{array}{c}\text { BCF } \\
\text { Linear }\end{array}$} & \multirow{2}{*}{$\begin{array}{l}\text { D-D } \\
\text { None }\end{array}$} \\
\hline & & $C D$ & $\begin{array}{c}G H H \\
\text { Baseline }\end{array}$ & $\underset{\text { (low Frisch) }}{G H H}$ & & \\
\hline & \multicolumn{6}{|c|}{ A. Stock and Bond Returns } \\
\hline$E\left(R^{e p}\right)$ & $6.17(1.99)$ & 2.65 & 4.21 & 4.03 & 6.63 & 5.23 \\
\hline$\sigma\left(R^{e p}\right)$ & $19.4(1.41)$ & 15.4 & 17.4 & 18.1 & - & 25.3 \\
\hline$\sigma\left(R^{s}\right)$ & $18.7(1.38)$ & 14.8 & 16.5 & 17.9 & 18.4 & 24.3 \\
\hline$E\left(R^{e p}\right) / \sigma\left(R^{e p}\right)$ & $0.32(0.11)$ & 0.17 & 0.24 & 0.22 & $0.36^{a}$ & 0.21 \\
\hline$E\left(R^{f}\right)$ & $1.94(0.54)$ & 2.87 & 1.42 & 1.73 & 1.20 & 1.32 \\
\hline$\sigma\left(R^{f}\right)$ & $5.44(0.62)$ & 4.91 & 4.10 & 4.46 & 24.6 & 10.61 \\
\hline \multicolumn{7}{|c|}{ B. Price-Dividend Ratio } \\
\hline$E\left(P^{s} / D\right)$ & $22.1(0.58)$ & 25.7 & 24.7 & 25.9 & - & - \\
\hline$\sigma\left(\log \left(P^{s} / D\right)\right)$ & $26.3(1.67)$ & 13.6 & 17.8 & 19.1 & - & - \\
\hline$\sigma(\Delta \log D)$ & $13.4(0.94)$ & 14.8 & 11.2 & 11.9 & - & 4.55 \\
\hline
\end{tabular}

${ }^{a} \mathrm{BCF}$ report the time average of the conditional Sharpe ratio, $E_{t}\left(R^{e p}\right) / \sigma_{t}\left(R^{S}\right)$, instead of the unconditional Sharpe ratio reported in the present paper. The statistics from BCF refer to their benchmark model (called the "preferred two sector model") and has the best overall performance. The statistics from Danthine and Donaldson (2002, D-D) are from their Table 6, right column with smoothed dividends, which generates the best overall performance. A "_" indicates that the corresponding statistic has not been reported in that paper. In column 4 , the Frisch elasticity is set to 0.5 , and the $\sigma_{\varepsilon}$ is recalibrated to $1.3 \%$ per quarter to match output volatility.

in the data, but higher than in the model with CD preferences. The volatility of dividend growth now falls to $11.2 \%$ annually. Overall, the model with GHH preferences display asset pricing behavior that is comparable to the model with inelastic labor supply.

In the next column, I explore the impact of lowering the Frisch elasticity closer to the values reported in the micro literature. I set $1 / \gamma$ to 0.5 following Domeij and Floden (2006), who survey existing micro studies and argue that part of the reason for the very low estimates is the bias arising from ignoring borrowing constraints. This change in calibration has a relatively modest effect on statistics: most notably, the equity premium falls slightly to $4 \%$ and the Sharpe ratio to 0.22. As I discuss in Section 6.1, the main drawback of this calibration is that it implies a labor hours process that is too smooth, which is also why macroeconomists typically use higher values similar to that in the baseline calibration.

It is useful to compare these results to earlier studies. In the working paper version, $\mathrm{BCF}$ show that introducing a flexible labor supply choice reduces the equity premium substantially, from $4.45 \%$ to $0.15 \%$, and the Sharpe ratio from 0.27 to $0.03 .{ }^{12}$ One goal of their paper, then,

\footnotetext{
${ }^{12}$ See Boldrin et al. (1999, Table II). The statement in the text is based on comparing the results in column
} 
is to identify some prominent labor market frictions that overcome this difficulty associated with endogenous labor supply. Their baseline model features such a framework that matches the historical equity premium as well as a number of other unconditional moments (reported in column 4 of Table III below).

In comparison, here flexible labor supply choice has a smaller negative impact on the Sharpe ratio, especially with GHH preferences. This difference stems from two sources. First, BCF employ a specification where utility is linear in leisure and separable from consumption. Consequently, fluctuations in labor hours have no direct effect on utility, which makes it relatively costless to smooth consumption fluctuations by adjusting one's labor supply. The only loss comes from the fact that to smooth fluctuations, labor supply would need to move in the opposite direction dictated by the substitution effect: rise in recessions when wages are low and fall in expansions when wages are high. In contrast, with the non-separable preferences in this paper, agents do care about fluctuations in leisure as well as how leisure co-moves with consumption, which makes it more costly to adjust labor supply to suppress fluctuations in the marginal utility of consumption. Second, with GHH preferences there is no wealth effect on labor supply choice, so labor hours are strongly procyclical due to the substitution effect of wages over the business cycle, making it an even less effective tool for smoothing fluctuations in marginal utility. As a result, the price of risk does not fall as much in this framework when labor supply choice is endogenized.

\subsection{The Dynamics of Asset Prices}

I now examine the extent to which the limited participation model captures some salient aspects of asset price dynamics. As mentioned earlier, some of these features, such as the countercyclical price of risk, have been difficult to generate in some asset pricing models. The results reported below are from the GHH model, but I found these statistics to be remarkably robust across the different specifications analyzed in this paper. ${ }^{13}$

\subsubsection{Mean Reversion and Predictability of Returns}

I begin with the price-dividend ratio, which is procyclical in the model, consistent with empirical evidence, with a correlation of 0.73 with output. The procyclicality follows from the fact that when the persistent technology shock hits the economy, the stock price capitalizes

4 to column 8 .

${ }^{13}$ The supplementary appendix reports the counterparts of the tables in this section for the CONS and CD models. 
Table IV: The Autocorrelation Structure of Key Financial Variables ${ }^{a}$

\begin{tabular}{lrrrrr}
\hline \hline & \multicolumn{7}{c}{ Autocorrelation at lag $j$ (years): } \\
\hline & 1 & 2 & 3 & 5 & 7 \\
\hline$r^{s}-r^{f}$ & & & & & \\
$\quad$ US Data & .03 & -.22 & .08 & -.14 & .10 \\
$\quad$ Model & -.03 & -.03 & -.02 & -.02 & -.02 \\
$\sum_{i=1}^{j} \rho\left[\left(r^{s}-r^{f}\right)_{t},\left(r^{s}-r^{f}\right)_{t-i}\right]$ & & & & & \\
$\quad$ US Data & .03 & -.19 & -.11 & -.29 & -.15 \\
$\quad$ Model & -.03 & -.06 & -.08 & -.13 & -.15 \\
\hline
\end{tabular}

${ }^{a}$ Statistics from the model are calculated from annualized values of each variable, except for the stock price, which is taken to be the value at the end of the year.

all future productivity gains upon impact and thus increases substantially, while the initial response of dividends is muted due to the gradual rise of the capital stock after the shock (because of adjustment costs), making the ratio of the two variables procyclical.

A second well-known observation concerning the equity premium is that it tends to revert to its mean over time. The first row of Table IV displays the autocorrelations of the equity premium from the US data. Notice that these autocorrelations are close to zero, which makes it difficult to measure them precisely. As a result, they are not uniformly negative. To circumvent this problem, an alternative statistic used in the literature aggregates consecutive autocorrelation coefficients, which reveals a stronger pattern of mean reversion (row 3). The second and fourth rows display the model counterparts of the two measures of mean reversion, which are consistent with the signs and rough magnitudes of these statistics in the data.

The finding of mean reversion is a clear departure from the martingale hypothesis of returns and is closely linked to the predictability of returns documented by Campbell and Shiller (1988), among others. To show this, I first regress log stock returns on the log pricedividend ratio using the historical US data (panel A of Table V). The well-known pattern documented in the literature can been seen here: the coefficients are negative, indicating that a high price-dividend ratio forecasts lower returns in the future. Moreover, both the coefficients and the $R^{2}$ values are increasing with horizon. The model counterpart is reported in the last two columns. The coefficient estimates and the $R^{2}$ s are consistent with empirical results: predictability is modest at the one-year horizon but increases steadily, reaching $35 \%$ at the seven year horizon. The coefficients also increase quickly first and then grow more 
Table V: Long-Horizon Regressions on Price-Dividend Ratio ${ }^{a}$

\begin{tabular}{|c|c|c|c|c|}
\hline \multirow[b]{2}{*}{ Horizon $(k)$} & \multicolumn{2}{|c|}{ US Data } & \multicolumn{2}{|l|}{ "Model } \\
\hline & Coefficient & $R^{2}$ & Coefficient & $R^{2}$ \\
\hline & \multicolumn{4}{|c|}{ A. Stock Returns } \\
\hline 1 & -.21 & .07 & -.19 & .09 \\
\hline 2 & -.36 & .12 & -.40 & .16 \\
\hline 3 & -.41 & .13 & -.49 & .22 \\
\hline 5 & -.70 & .23 & -.77 & .28 \\
\hline \multirow[t]{2}{*}{7} & -.87 & .27 & -.91 & .35 \\
\hline & \multicolumn{4}{|c|}{ B. Excess Returns } \\
\hline 1 & -.22 & .09 & -.11 & .02 \\
\hline 2 & -.39 & .14 & -.20 & .04 \\
\hline 3 & -.47 & .15 & -.29 & .06 \\
\hline 5 & -.77 & .26 & -.42 & .10 \\
\hline 7 & -.94 & .33 & -.49 & .12 \\
\hline
\end{tabular}

${ }^{a}$ The table reports the coefficients and $R^{2}$ values of the regression of log stock returns (top panel) and log excess returns (bottom panel) on the log price-dividend ratio. Horizon $(k)$ is in years.

slowly. Overall, the model generates significant predictability of stock returns.

Turning to excess returns in panel B (first four columns), the predictability in the US data is evident again. The last two columns report the same regressions using simulated data. The coefficients on the price-dividend ratio are negative and increase in absolute value with horizon consistent with the data. However, the amount of predictability is smaller than in the data: the $R^{2}$ of the regression is only $12 \%$ at the seven year horizon compared to $33 \%$ in the data. Thus, the model is qualitatively consistent with excess return predictability, but does not quantitatively capture the total magnitude observed in the US data.

\subsubsection{Countercyclical Variation in the Price of Risk}

I now examine the cyclical behavior of the conditional moments. Figure 2 plots the typical simulated paths of the expected equity premium and Sharpe ratio against output over a period of 200 years. ${ }^{14}$ Consistent with the US data (Chou et al. (1992)), both the expected premium and the Sharpe ratio rise visibly in recessions and fall in expansions (correlation with output: -0.55 and -0.63 , respectively). Moreover, the conditional volatility is also

\footnotetext{
${ }^{14}$ Each series is rescaled by its standard deviation and shifted vertically to fit in the same graph. Thus, while the amplitudes are not informative, the comovement between the series is preserved.
} 
Figure 2: The cyclical behavior of expected excess returns and the Sharpe ratio.

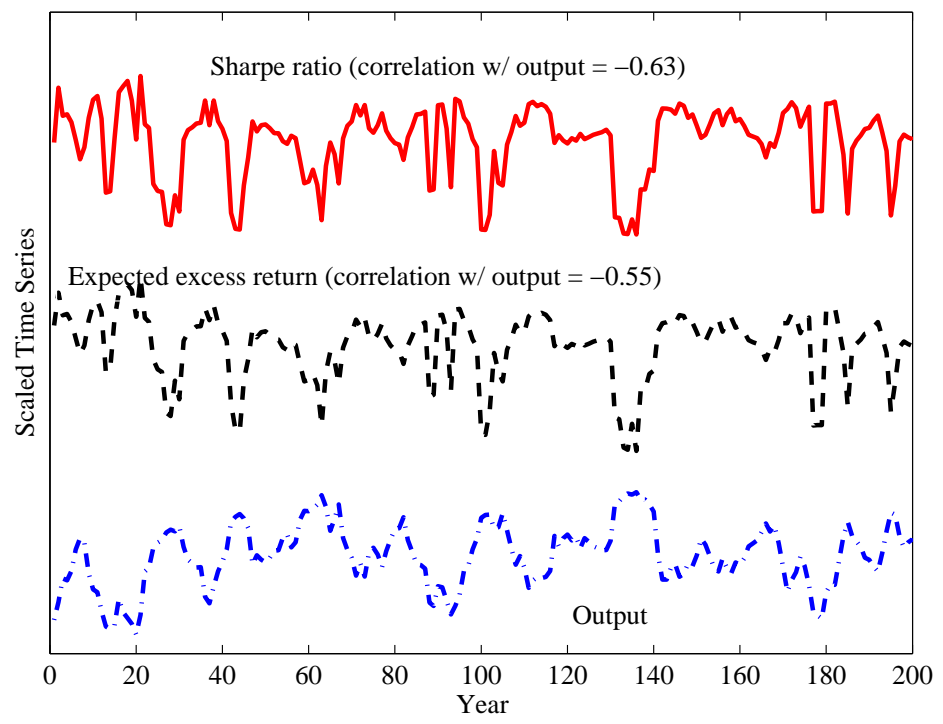

countercyclical with a correlation with output of -0.42 (to save space, the plot is not included in the figure). The conditional moments are also quite variable: the $95 \%$ confidence interval for the expected excess return extends from $1.3 \%$ to $4.8 \%$, and the $95 \%$ confidence interval for its conditional volatility extends from $9.1 \%$ to $18.5 \%$. The fact that expected returns are more variable than conditional volatility (as measured by their coefficient of variation) results in the countercyclicality of the Sharpe ratio mentioned above. With few exceptions, ${ }^{15}$ this countercyclicality of the market price of risk has been difficult to generate in consumptionbased asset pricing models. In the next section, I explain the new mechanism in this model which generates this result.

\section{$5 \quad$ Understanding the Sources of Equity Premium}

The large and countercyclical equity premium arises from the interaction of (i) limited stock market participation; (ii) the low EIS of non-stockholders; and (iii) consumption smoothing in the face of persistent (aggregate) labor income shocks. What distinguishes the mechanism in this paper from earlier models of limited participation is (ii) and (iii), which makes the timing of trade in the bond market the driving force behind the high equity premium. In this section I quantify this mechanism. Because labor supply choice adds another level of complexity to the analysis, in this section I focus on the CONS model.

\footnotetext{
${ }^{15}$ Most notably, Campbell and Cochrane (1999) and Bansal and Yaron (2004).
} 


\subsection{Why Is There a High Equity Premium?}

The annual standard deviation of consumption growth in the CONS model is $3.61 \%$ for stockholders but only $1.48 \%$ for non-stockholders. To quantify the sources of stockholders' consumption volatility, I first substitute the equilibrium conditions (3-a,b) as well as the expression for dividends into the budget constraint of a stockholder, and after some straightforward manipulation I obtain:

$$
c^{h}=\underbrace{\left(W+\frac{\theta Z K^{\theta} L^{1-\theta}-I}{\mu}\right)}_{A^{h}}-\underbrace{\frac{\left(B-P^{f} B^{\prime}\right)}{\mu}}_{a^{h}}
$$

This expression provides a useful decomposition. Part of the variation in stockholders' consumption comes from aggregate sources, that is, fluctuations in wage and capital income, which is denoted by $A^{h}$. The scaling factor $1 / \mu$ that appears in $A^{h}$ reflects the fact that aggregate capital income risk is concentrated among stockholders, since they are the sole capital owners in this economy. However, this risk only has a modest contribution to the volatility of their consumption, as will become clear shortly. A second part of variability arises from trade with the non-stockholders in the bond market: the component denoted by $a^{h} \equiv\left(B-P^{f} B^{\prime}\right) / \mu$ measures the net interest payments received by non-stockholders, which is made by stockholders indirectly through the firm they own. Using equation (10), stockholders' consumption growth volatility can be approximated as:

$$
\operatorname{var}\left(\Delta \log c^{h}\right) \approx \operatorname{var}\left(\Delta \log A^{h}\right)+\operatorname{var}\left(\Delta \frac{a^{h}}{A^{h}}\right)+2 \operatorname{cov}\left(\Delta \log A^{h},-\Delta \frac{a^{h}}{A^{h}}\right) .
$$

Similarly, non-stockholders' consumption can be written as: $c^{n}=W+\left(B-P^{f} B^{\prime}\right) /(1-\mu)$, and the variance of their consumption growth is obtained by replacing $A^{h}$ and $a^{h}$ in equation (11) with $A^{n} \equiv W$ and $a^{n} \equiv-a^{h} \mu /(1-\mu)$, respectively.

The top panel of Table VI shows that interest payments are very small on average, making up a small fraction of consumption: $E\left(a^{i}\right) / E\left(c^{i}\right)$ is less than $1.01 \%$ for both stockholders and non-stockholders. However, interest payments are volatile, and more importantly, they vary systematically with the business cycle. This is shown in the lower panel, which displays the fraction of consumption growth variance explained by each of the three terms in equation (11). For stockholders, only $18.5 \%$ of consumption growth variance is attributable to fluctuations in aggregate income, despite the fact that this component makes up nearly 
Table VI: Decomposition of Consumption Volatility and Equity Premium ${ }^{a}$

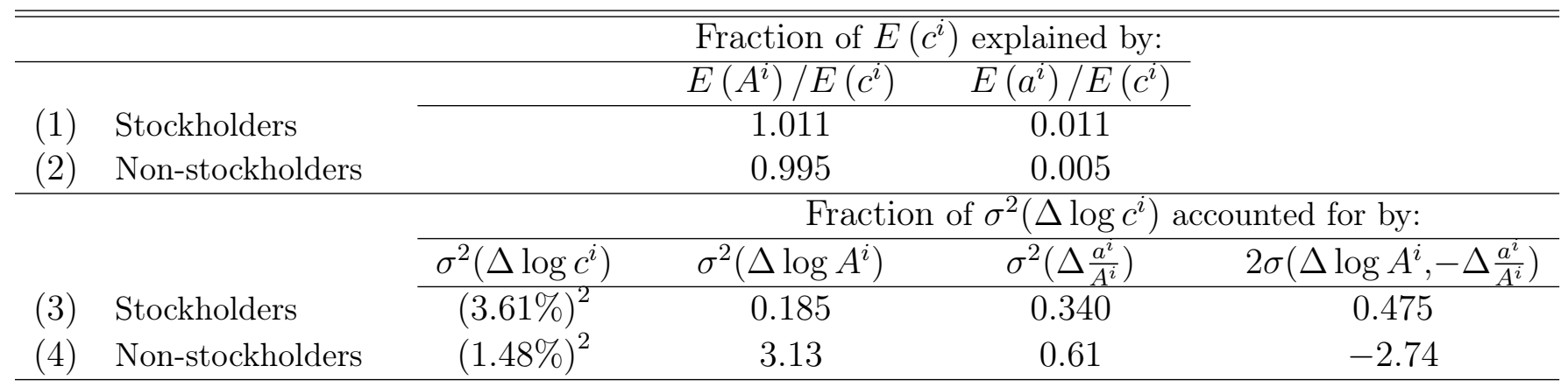

${ }^{a} i=h, n$. See the text and equation (10) for the definitions of $a^{i}$ and $A^{i}$

all of their average consumption (row 1). Hence, the concentration of aggregate capital income risk, included in $A^{h}$, contributes only modestly to consumption fluctuations, and consequently to the equity premium. The main source of volatility for stockholders comes from the bond market: interest payments, $a^{h}$, account for the remaining three-quarters of variance $(0.34+0.475)$. What is really crucial for this extra volatility is the timing of interest payments: $\operatorname{corr}\left(\Delta \log A^{h}, \Delta\left(a^{h} / A^{h}\right)\right)=-0.947$ (which can be calculated from row 3 of Table VI), which means that the payments received by the non-stockholders increase exactly when aggregate income falls, i.e., in recessions. ${ }^{16}$ Therefore, consumption smoothing for non-stockholders comes at the expense of large fluctuations in stockholders' consumption, so the covariance term in the third column accounts for nearly half of the total volatility. The flip side of this story is seen in the variance of non-stockholders: $\operatorname{var}\left(\Delta \log c^{n}\right)$ would be 3.13 times higher, were it not for the consumption smoothing provided by stockholders through the bond market (that is, if the bond market were shut down, so $a_{t}^{h} \equiv 0$ ).

A Comparison to Earlier Models. The mechanism proposed in this paper differs from earlier models with limited participation in two key dimensions. First, in Saito (1995) and Basak and Cuoco (1998) non-stockholders begin life with some financial wealth but do not have a labor income flow. The only way to sustain consumption is then by investing this wealth in the bond market. As a result, each period non-stockholders receive substantial interest payments from stockholders, which in turn leverages the capital income of the latter group and amplifies their consumption volatility. Although this is a potentially powerful

\footnotetext{
${ }^{16}$ This negative correlation is not due to the appearance of $A^{h}$ in the first term as well as in the denominator of the second term. To verify this, I also calculated $\operatorname{corr}\left(\Delta \log A^{h}, \Delta a^{h}\right)=-0.953$, which is as negative as the reported correlation.
} 
mechanism, for it to work, interest payments needs to be substantial — as large as the consumption of non-stockholders - which in turn implies that non-stockholders must hold a large fraction of aggregate wealth. This counterfactual implication has been one of the main criticisms raised against these models. In contrast, as noted above, the interest payments in the present model are very small, and as we shall see below, the fraction of aggregate wealth held by non-stockholders is also small and consistent with empirical evidence. Instead, the amplification here is generated by the cyclical nature of these payments that serve to insure non-stockholders against aggregate fluctuations.

The mechanism in Danthine and Donaldson (2002) is more closely related to the present paper. In their model, entrepreneurs smooth fluctuations in their workers' consumption at the expense of extra volatility in their own consumption, which results in a high equity premium. An important difference from the present model is that this smoothing happens through insurance within the firm, instead of being through the bond market. As a result, the bond price is determined by the entrepreneurs alone (and not jointly with workers, which is the case here). It would be interesting to know if this difference would result in different implications for asset price dynamics, which is not explored in that paper.

A second difference from previous models is that here preference heterogeneity is essential for amplifying stockholders' consumption volatility relative to that of non-stockholders. This point has already been discussed in Section 4.2, so I do not repeat it here. But it is important to note that this feature contrasts with the previous papers mentioned above, where nonstockholders have no choice but to lend to stockholders simply to survive, which amplifies the consumption volatility of the latter group regardless of preference heterogeneity.

Empirical Evidence. Finally, the high volatility of stockholders' consumption relative to that of non-stockholders is well documented empirically. For example, Mankiw and Zeldes (1991) find the ratio of standard deviations to be 1.6 using PSID data, although their consumption measure consists of only food expenditures, which is likely to understate the true volatility ratio for non-durables. Attanasio, Banks, and Tanner (2002) use expenditures on non-durables and services from the UK Family Expenditure Survey and calculate stockholders' volatility to be 1.5 to 2 times larger than that of non-stockholders. ${ }^{17}$ Another piece of evidence comes from A"1t-Sahalia, Parker and Yogo (2004) who document that the sales of luxury goods (such as expensive French wine, charitable donations, rents on luxury condos

\footnotetext{
${ }^{17}$ These figures are likely to be downward biased because existing measures of stockholders' consumption are based on micro data sets that contain few "extremely rich" households, i.e., those in the top 1\% of the wealth distribution. At the same time, these households own nearly half of all stocks, and the top $0.5 \%$ own $37 \%$ of all stocks (Poterba and Samwick (1995)).
} 
in Manhattan, etc.) display volatility that exceeds the standard deviation of aggregate nondurables consumption by a factor of 5 to 10 . They interpret this finding as indicative of highly volatile expenditures by the very wealthy.

\subsection{Why Is the Equity Premium Countercyclical?}

It is instructive to start from the following decomposition of the conditional Sharpe ratio that can be derived under CRRA preferences. ${ }^{18}$ Although I use recursive utility in the present model, it turns out that the same decomposition still holds fairly well here, and is useful for understanding the source of time variation: ${ }^{19}$

$$
S R_{t} \equiv \frac{E_{t}\left(R_{t+1}^{e p}\right)}{\sigma_{t}\left(R_{t+1}^{e p}\right)} \approx \alpha^{h} \times \sigma_{t}\left(\Delta \log c_{t+1}^{h}\right) \times \operatorname{corr}_{t}\left(\Delta \log c_{t+1}^{h}, R_{t+1}^{e p}\right)
$$

The conditional correlation term in (12) is close to 1 and is very stable over the business cycle, and $\alpha^{h}$ is simply a constant. Therefore, equation (12) points to $\sigma_{t}\left(\Delta \log c_{t+1}^{h}\right)$ as the source of time-variation in the Sharpe ratio. Indeed, in the model, $S R_{t}$ is $48 \%$ higher during a recession than it is in a boom, and $\sigma_{t}\left(\Delta \log c_{t+1}^{h}\right)$ is $39 \%$ higher in a recession than in a boom, explaining a large fraction of the countercyclicality in $S R_{t}{ }^{20}$ Moreover, because conditional volatility, $\sigma_{t}\left(R_{t+1}^{e p}\right)$, is also countercyclical- $18 \%$ higher during recessions - the expected equity premium, $E_{t}\left(R_{t+1}^{e p}\right)$, is $68 \%$ higher during recessions compared to booms.

The natural question that follows is: Why is the stockholders' consumption growth volatility countercyclical? To answer this question, two points should be noted. First, a well-known feature of the consumption-savings problem in the presence of uninsurable income risk is that the value function has more curvature at lower wealth levels and less curvature at higher wealth levels. While this is well-known in the expected utility case, the same is true here with recursive preferences, as can be seen from Figure 3, which plots how

\footnotetext{
${ }^{18}$ Two additional assumptions that are needed for deriving the decomposition are that portfolio constraints are not binding, and consumption growth and asset returns are homoskedastic and jointly log-normal.

${ }^{19}$ Although one can also derive an exact decomposition of the Sharpe ratio with recursive preferences (Campbell (1999, eq. 22)), I do not use this alternative form because (i) it requires the additional assumption of complete markets (or human wealth to be tradeable); and (ii) the decomposition has the same form as the one used here, but adds a second term that involves the covariance of the equity premium with the return on wealth. The contribution of this second term depends on the values of risk aversion and EIS and, for the values used in this paper, it does not seem to be of first order importance for the cyclical behavior. Therefore, I opt for the simpler decomposition. which is useful for discussing the mechanism.

${ }^{20} \mathrm{~A}$ recession is defined as the states of the world when output is one standard deviation or more below the mean, ie., $Y_{t}<E(Y)-\sigma(Y)$. An expansion is defined analogously: $Y_{t}>E(Y)+\sigma(Y)$. Using average output as the dividing line, I get: $\left.\left.E\left[\sigma_{t}\left(\Delta c_{t+1}^{h}\right) \mid Y_{t}<E(Y)\right)\right] / E\left[\sigma_{t}\left(\Delta c_{t+1}^{h}\right) \mid Y_{t}>E(Y)\right)\right]=1.23$.
} 
Figure 3: Change in the slope of value functions with wealth level
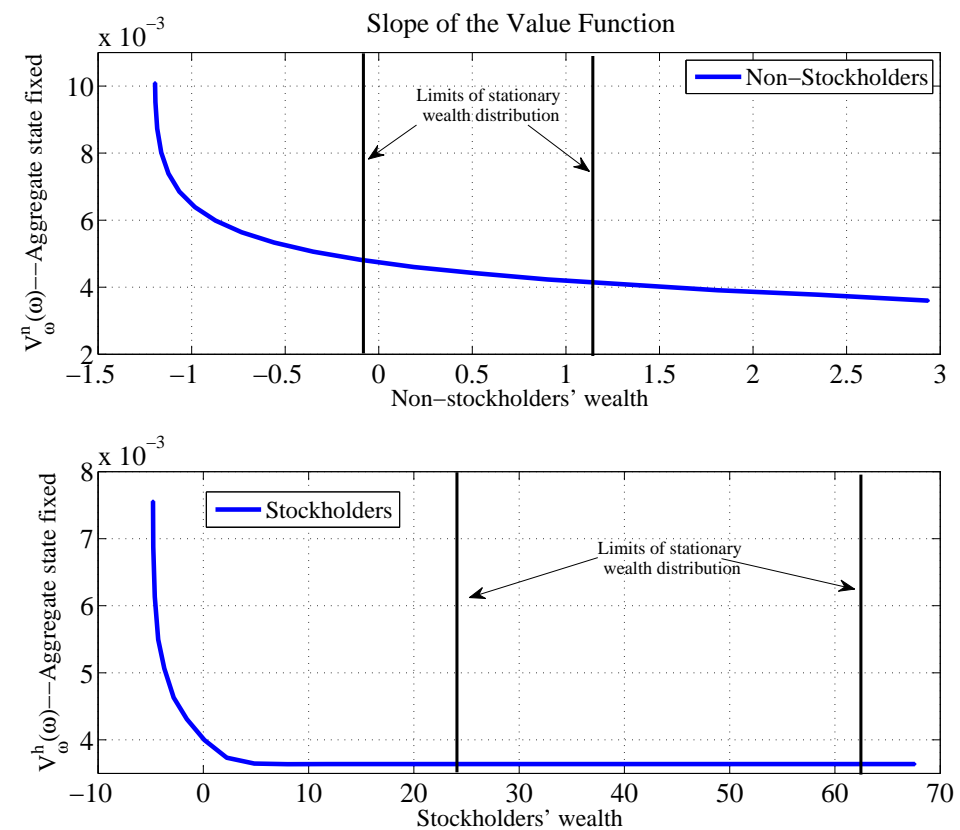

the slopes of $V^{h}$ and $V^{n}$ change with $\omega$ (keeping aggregate state variables fixed). If markets were complete, with the formulation of recursive preferences in (1) the value functions would be linear in wealth (Epstein (1988)), implying that the slopes would be constant in wealth. This is obviously not the case for either agent in Figure 3, owing to incomplete markets.

Moreover, and thus second, non-stockholders own substantially less wealth per capita than stockholders (more on this in Section 6.3). Figure 3 shows the bounds of the ergodic distribution of wealth for each type of agent, where this difference in wealth levels is evident. Thus, non-stockholders are on the part of their value function that has high curvature and a relatively small change in their wealth holdings changes their attitudes toward risk and, consequently, changes their precautionary savings demand significantly. This is clearly not the case for stockholders who remain on the very flat part of their value function over the business cycle. To further illustrate this point, Figure 4 plots the normalized curvature of the value function (i.e., risk aversion with respect to wealth gambles), $-\omega V_{\omega \omega}^{i} / V_{\omega}^{i}$, for each type of agent as a function of realized output using simulated data from the CONS model. ${ }^{21}$ I normalize the average value to 1 for both groups so that the vertical axis can be interpreted as the percentage change in risk attitudes over the business cycle. The effect described above can be clearly seen here: non-stockholders' risk aversion increases significantly

\footnotetext{
${ }^{21}$ Risk aversion with respect to wealth gambles depends on the market structure in addition to $\alpha$.
} 
Figure 4: Change in attitudes toward risk over the business cycle
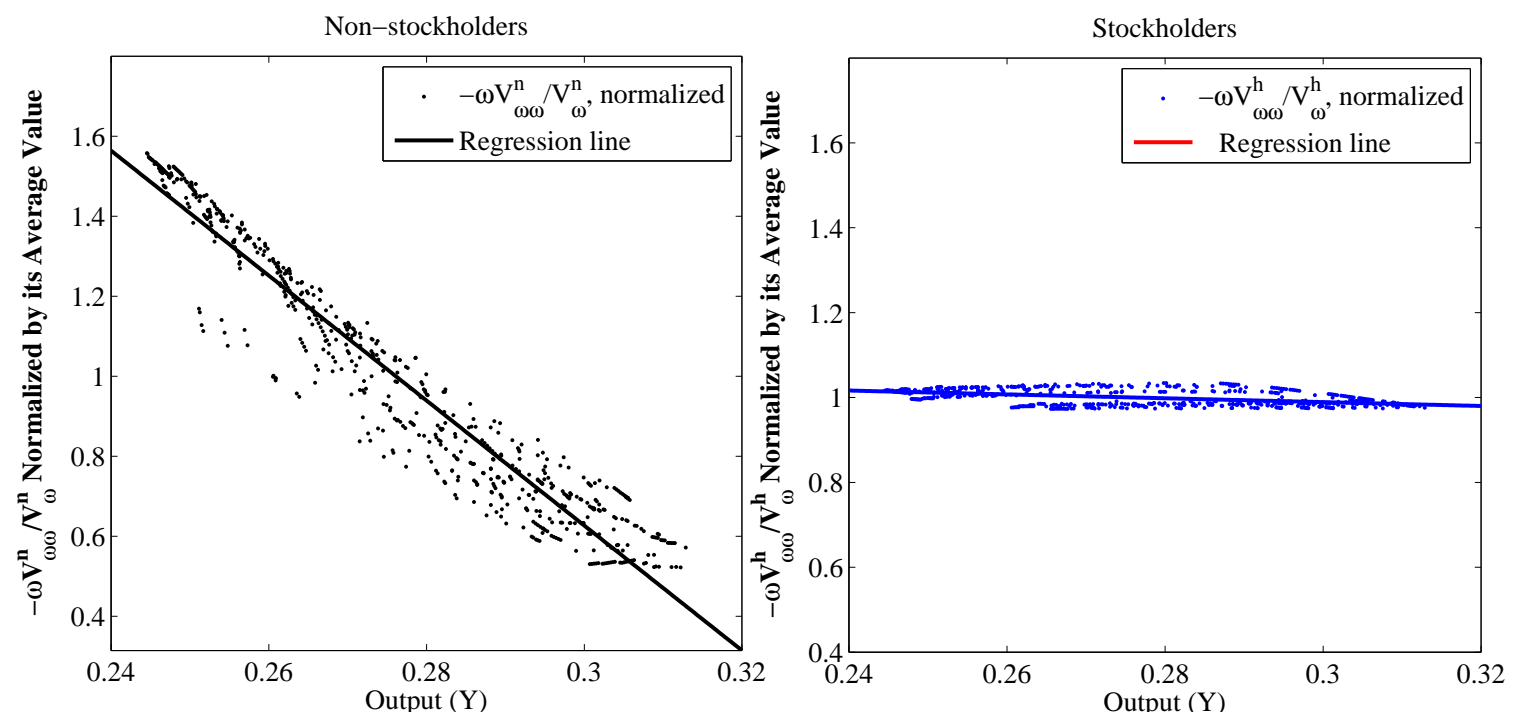

in recessions (and consequently, their demand for insurance), whereas it barely moves for stockholders. Combining this countercyclical change in non-stockholders' demand for consumption smoothing with the mechanism described in the previous section implies that there should be more trade in the risk-free asset market in recessions. This is exactly what happens: $\rho\left(\left|a_{t}^{h}\right|, Y_{t}\right)=-0.55$, which shows that the average size of interest payments increases - in turn raising stockholders' consumption growth volatility-during recessions. ${ }^{22}$

Finally, in contrast to the $39 \%$ rise in $\sigma_{t}\left(\Delta \log c_{t+1}^{h}\right)$ mentioned above, $\sigma_{t}\left(\Delta \log c_{t+1}^{n}\right)$ goes down slightly - by 10\% - in recessions. Of course, this is entirely consistent with the mechanism discussed above whereby non-stockholders have an even stronger desire for a smooth consumption process during recessions. But, because the two groups' conditional volatilities move in opposite directions over the business cycle, aggregate consumption growth volatility exhibits little time variation (goes up by only $8 \%$ in recessions), masking the large cyclical changes in $\sigma_{t}\left(\Delta \log c_{t+1}^{h}\right)$ responsible for the countercyclical Sharpe ratio. A corollary to this observation is that if a researcher studies equation (12) with the aggregate consumption process (as would be the case in a representative agent framework), the lack of time variation in the volatility of aggregate consumption growth would lead the researcher to require the

\footnotetext{
${ }^{22}$ Notice that the countercyclicality of trade volume reflects larger transfers of both signs in the bond market during recessions. This can be seen more clearly by calculating: $E\left(a_{t}^{h} \mid\right.$ recession, $\left.\Delta Y_{t}<0\right)=0.62>0.40=$ $E\left(a_{t}^{h} \mid\right.$ boom, $\left.\Delta Y_{t}<0\right)$, and $E\left(a_{t}^{h} \mid\right.$ recession, $\left.\Delta Y_{t}>0\right)=-0.66<-0.43=E\left(a_{t}^{h} \mid\right.$ boom, $\left.\Delta Y_{t}>0\right)$. Thus, because non-stockholders are more averse to fluctuations during recessions, they borrow more aggressively when they receive a negative shock to prevent an immediate fall in consumption; and when they receive a positive shock, they save more aggressively as a buffer stock to self-insure against future negative shocks.
} 
Table VII: Business Cycle Statistics in the US Data and in the Model ${ }^{a}$

\begin{tabular}{|c|c|c|c|c|c|c|}
\hline \multirow[b]{2}{*}{ Leisure preferences } & \multirow[t]{2}{*}{ Data } & \multicolumn{3}{|c|}{ Model } & \multirow{2}{*}{$\begin{array}{l}\mathrm{BCF} \\
\text { linear }\end{array}$} & \multirow{2}{*}{$\begin{array}{l}\text { D-D } \\
\text { none }\end{array}$} \\
\hline & & CD & $\begin{array}{c}\text { GHH } \\
\text { Baseline }\end{array}$ & $\begin{array}{c}\mathrm{GHH} \\
\text { low Frisch }\end{array}$ & & \\
\hline & \multicolumn{6}{|c|}{ Volatility } \\
\hline$\sigma(Y)$ & $1.89(.21)$ & 1.97 & 1.95 & 1.96 & 1.97 & 1.77 \\
\hline$\sigma(C) / \sigma(Y)$ & $0.40(.04)$ & 0.92 & 0.78 & 0.75 & 0.69 & 0.82 \\
\hline$\sigma(I) / \sigma(Y)$ & $2.39(.06)$ & 1.38 & 1.76 & 1.86 & 1.67 & 1.72 \\
\hline \multirow[t]{2}{*}{$\sigma(L) / \sigma(Y)$} & $0.80(.05)$ & 0.07 & 0.50 & 0.32 & 0.51 & - \\
\hline & \multicolumn{6}{|c|}{ Correlation with Output } \\
\hline$\rho(Y, C)$ & $0.76(.05)$ & 0.99 & 0.99 & 0.99 & 0.95 & 0.96 \\
\hline$\rho(Y, I)$ & $0.96(.01)$ & 0.99 & 0.94 & 0.97 & 0.97 & 0.93 \\
\hline$\rho(Y, L)$ & $0.78(.05)$ & 0.96 & 0.98 & 0.99 & 0.86 & - \\
\hline
\end{tabular}

${ }^{a}$ The statistics for the US data are taken from Table 1 in BCF. The model statistics are computed after simulated data have been aggregated to quarterly frequency, logged, and then HP filtered.

curvature parameter, $\alpha$, to be time-varying in order to explain the countercyclicality of $S R_{t}$. This is the approach adopted, for example, in Campbell and Cochrane (1999) among others.

\section{Model Results: Macroeconomic Quantities}

In this section I examine the implications of the model for macroeconomic quantities along two dimensions. I first analyze the performance of the model for business cycle statistics and then turn to the cross-sectional implications.

\subsection{Business-Cycle Implications}

Table VII displays standard business cycle statistics from the US data as well as their counterparts from the CD and GHH models. As before, the last two columns report the corresponding figures from BCF and Danthine and Donaldson (2002) for comparison.

CD Model. In column 2, the first row reports the volatility of output, which was one of the two calibration targets and is matched fairly well. The volatility of consumption (normalized by that of output) is about 0.4 in the US data, but is overstated at 0.92 in the model. In contrast, investment is too smooth, with a volatility of 1.38 in the model compared to 2.39 in the US data. Although these discrepancies are bothersome, the most glaring shortcoming of the CD model is seen in the behavior of labor hours, which is an order of magnitude 
too smooth compared to data (0.07 versus 0.80$)$. However, the behavior of the aggregate labor supply masks significant heterogeneity between the two groups' behavior. In particular, labor hours are quite volatile but countercyclical for stockholders $\left(\sigma\left(l^{h}\right) / \sigma(Y)=0.77\right.$; correlation with output: -0.96$)$, whereas it is procyclical but smoother for non-stockholders because of their low Frisch labor supply elasticity $\left(\sigma\left(l^{n}\right) / \sigma(Y)=0.24\right.$; correlation: +0.97$)$. The behavior of aggregate hours largely mirrors that of non-stockholders (i.e., procyclical and smooth), because they make up a substantial majority of the population. However, aggregate hours are even smoother than that of non-stockholders, exactly because the labor supply of the two groups moves in opposite directions over the business cycle, partly canceling each other. To increase the volatility of aggregate hours, one would need to increase the Frisch elasticity of non-stockholders and/or assume a smaller fraction of households to be stockholders. Unfortunately, a higher Frisch elasticity also means a higher EIS for nonstockholders, which contradicts the main empirical evidence this paper builds upon. Because of this important shortcoming, I conclude that Cobb-Douglas utility does not appear to be a promising direction to pursue in this framework for endogenizing labor supply.

Procyclicality of Aggregate Hours. Despite the important shortcomings of the CD model, the procyclical aggregate hours is an encouraging finding, in light of earlier studies that have consistently found that capital adjustment costs create countercyclical hours in representative agent models (cf., BCF and Uhlig (2006)). Thus, it is important to understand why the present model delivers the opposite result. The answer lies in the specific nature of the cross-sectional heterogeneity generated by limited participation. To see why this helps, first note that adjustment costs generate a volatile and procyclical stock price (as in the data). In a representative agent model, such as the one studied by BCF, this implies a large positive wealth effect during expansions, which overcomes the substitution effect from a higher wage rate and causes labor hours to drop during expansions. In contrast, here $80 \%$ of the population are non-stockholders and therefore do not experience the described wealth effect. Instead, they mainly respond to the substitution effect of higher wages and increase their labor hours. Although stockholders behave in a similar fashion to the representative agent described above, they only make up a small fraction of the population. This result therefore suggests that the countercyclical hours found in earlier studies arises from the interaction of adjustment costs with the representative agent assumption. By relaxing the latter, the present model is able to generate procyclical hours with Cobb-Douglas preferences. 
GHH Model. Turning to the GHH model, the volatility of consumption is lower, whereas the volatility of investment is higher compared to the CD model, and the model is now in the same ballpark as the other two macro-asset pricing models reported in the table. The more significant improvement is in the volatility of labor hours, where the CD model failed most dramatically: now, the volatility of hours is much higher than before (equal to half the volatility of output) and is closer to the data. This improvement is due to the flexibility afforded by GHH preferences for calibrating the Frisch elasticity independently of the EIS. Aggregate hours (as well as each group's labor hours) are also procyclical, which is due to the lack of wealth effects with GHH preferences. Finally, column 3 reports the statistics from the GHH model when Frisch elasticity is lowered to 0.5. As seen here, the major impact of this change is a large fall in the volatility of labor hours, which is a major reason why macroeconomic studies typically use higher values as in the baseline calibration. To sum up, the macroeconomic implications of GHH preferences are tolerable-i.e., comparable to previous macro-asset pricing models - and are significantly better than the CD model.

\subsection{Asset Prices versus Macro Performance: Some Trade-offs}

As noted earlier, there is a fair amount of uncertainty regarding the values of some key model parameters, most notably $\xi$ and $\alpha^{h}$. Therefore, I now examine the effect on asset prices and macroeconomic volatilities of varying these two parameters over a plausible range.

I first consider variations in the adjustment cost parameter around its baseline value of 0.4. As $\xi$ is raised from 0.2 to 0.7 , it becomes less costly for stockholders to adjust the level of capital installed in the firm, which makes investment a more effective tool for consumption smoothing. The effect can be seen in the right panel of Figure 5 (circles), which plots the combinations of investment volatility and consumption volatility (scaled by output volatility) implied by the model for each value of $\xi$. The baseline case is marked by the intersection of the dashed horizontal and vertical lines. As $\xi$ rises, investment becomes much more volatile (rises from 1.16 to 2.33) while consumption becomes smoother (from 0.96 to 0.67), bringing both statistics closer to their empirical counterparts (although the lowest volatility figure for consumption is still higher than the 0.40 value in the US data).

Not surprisingly, however, lower adjustment costs and the resulting smoothness of consumption also affect asset prices. This is shown in the left panel, which plots the combinations of equity premium and Sharpe ratio implied by each value of $\xi$. Raising $\xi$ from 0.2 to 0.7 reduces the equity premium by a factor of about 1.2 (from $8.20 \%$ to $3.67 \%$ ), which is mostly

driven by a lower volatility of returns (from $28.1 \%$ to $16.1 \%$ ). As a result, the fall in the 
Figure 5: Trade-off between asset prices and macroeconomic volatilities
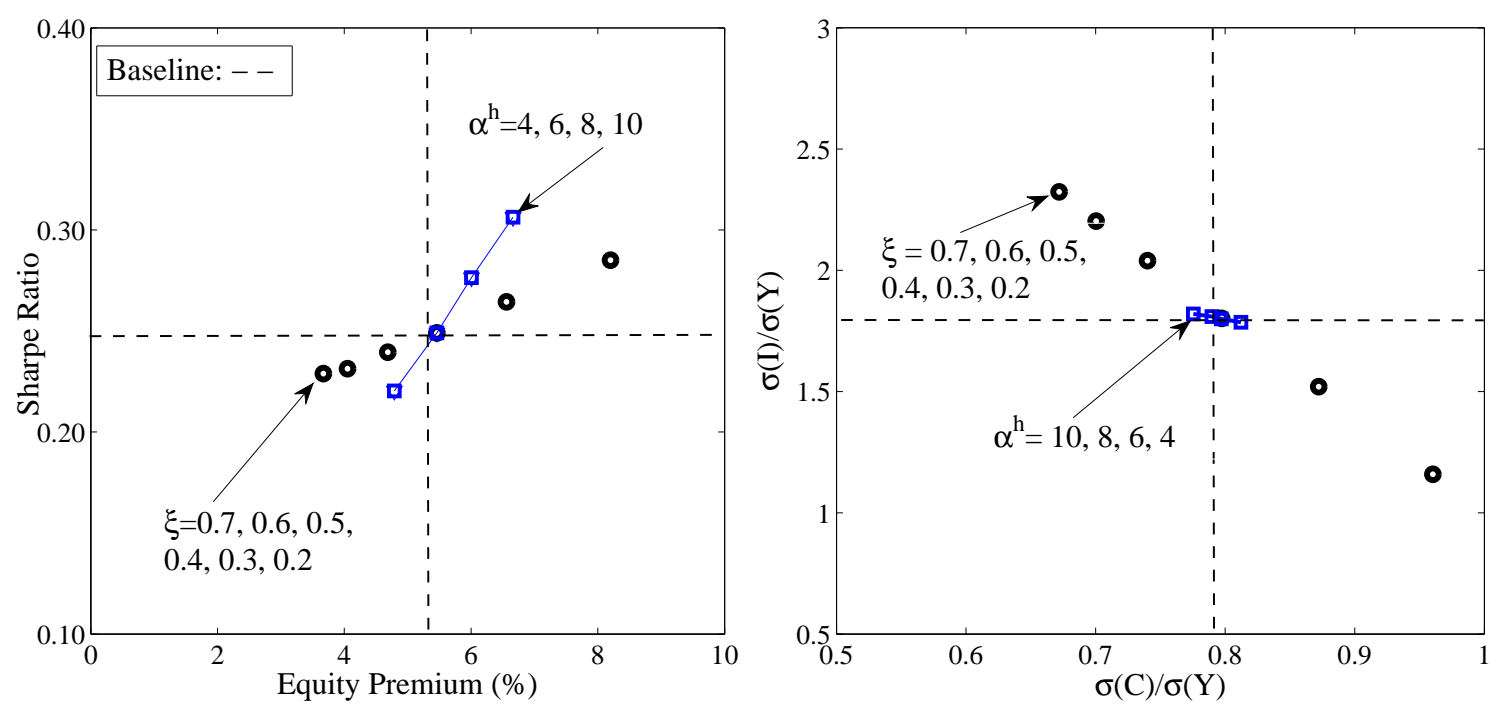

Sharpe ratio is a rather small $24 \%$ (from 0.285 to 0.229 ). This comparison suggests that the model's implications for macro volatilities can be improved, at the expense of a smaller equity premium and a slightly lower Sharpe ratio.

Next I turn to the risk aversion of stockholders and consider values of $\alpha^{h}$ from 4 to 10 . Starting in the right panel (marked by "squares"), notice that increasing risk aversion has a very minor impact on the volatilities of investment and consumption (although, qualitatively, it moves the model in the right direction). It does however have a more significant impact on asset prices (left panel): the equity premium rises from $4.79 \%$ to $6.65 \%$ with an almost equal rise in the Sharpe ratio (from 0.221 to 0.306 ).

These two exercises illustrate the trade-offs between the asset pricing and macroeconomic implications of the model. Together, they suggest that if one is willing to tolerate a risk aversion as high as 10 for stockholders, adjustment costs could be reduced to, for example, $\xi=0.6$. The higher risk aversion would deliver a sizeable equity premium and Sharpe ratio, while the low adjustment cost would move macroeconomic volatilities closer to the data. Nevertheless, a risk aversion of 10 seems quite high, especially for stockholders who are willingly undertaking substantial risks in financial markets.

\subsection{Distributional Implications}

Given the central role played by heterogeneity for the asset pricing results of this paper, an important question to ask is whether or not the implied cross-sectional behavior is broadly 
Figure 6: Evolution of wealth distribution over time

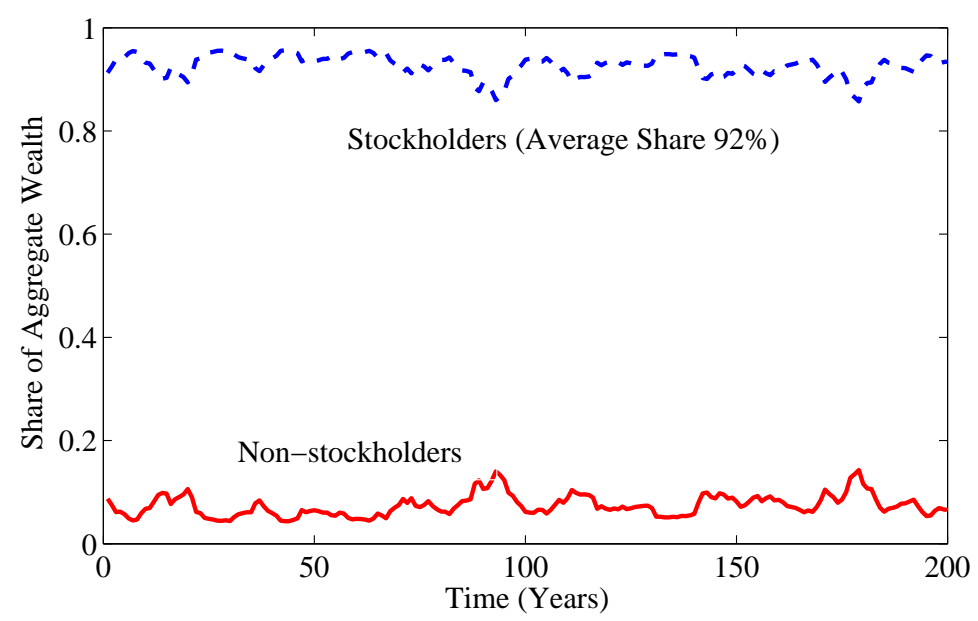

consistent with empirical evidence. I first look at the wealth distribution implied by the GHH model (Figure 6), which reveals substantial inequality between the two groups: on average stockholders own $92 \%$ of aggregate wealth, whereas non-stockholders own the remaining $8 \%$. (These shares are fairly robust across specifications: stockholders' share is $86 \%$ in the CD model and $89 \%$ in the CONS model.) These figures compare fairly well to the US data, where in the 1980s and 1990s stockholders owned an average of $82 \%$ of all net worth (fungible wealth, including housing) and more than $90 \%$ of financial assets (see Poterba and Samwick (1995) and Guvenen (2006)). As noted above, this implication for wealth inequality is an important difference between the present model and earlier models with limited participation, which required substantial wealth holdings for non-stockholders.

This discussion, however, raises a question of its own: Is the amount of trade in the risk-free asset implied by the model quantitatively plausible, or do we need a substantial amount of trade to sustain the mechanism that generates the equity premium? One way to answer this question is by looking at the trade volume, which I define as the (absolute) change in non-stockholders' bond holdings during a given year compared to the level of their bond holdings: $E(|\Delta B|) / E(B)$. This measure is less than $1.1 \%$ per year across all versions of the model reported in Tables 2 and 3. This modest figure perhaps does not come as a surprise, given the gradual shifts in the wealth shares shown earlier in Figure 6. As an alternative measure, I compare the size of non-stockholders' per capita transactions to their wage income: $E\left(\frac{\left|B-P^{f} B^{\prime}\right|}{1-\mu}\right) / E(W)$ is less than $1.9 \%$ annually across all simulations. ${ }^{23}$ For a non-stockholding household with an annual income of $\$ 50,000$, this upper bound implies a

${ }^{23}$ To construct the measure, I first annualize the total transactions by adding up $B_{t}-P_{t}^{f} B_{t+1}$ over 12 
net change, for example in their savings account, of $\$ 950$ during the year. These relatively small payments entail large changes in stockholders' consumption, because they are synchronized across all non-stockholders (i.e., they result from aggregate shocks) and the effect is concentrated among a small number of stockholders. ${ }^{24}$

\section{Conclusions}

I have studied the implications of a two-agent model with limited stock market participation and heterogeneity in the EIS for asset prices and macroeconomic quantities. My findings suggest that the cross-sectional heterogeneity generated by the interaction of these two features could be important for several macro-asset pricing phenomena.

The model highlights a new mechanism for the equity premium that results from the limited consumption smoothing opportunities available to the majority of the population, who are non-stockholders. These households turn to the bond market, which effectively transfers their (aggregate) labor income risk and concentrates it among a small group of stockholders. As a result, these households demand to be compensated in the form of a high equity premium. In addition to generating broadly plausible behavior for asset prices, this mechanism is also consistent with the very low wealth holdings of non-stockholders in the US data, which has been problematic for previous models of limited participation. This significant skewness in wealth holdings, in turn, combines with the basic mechanism above to provide a novel explanation for the countercyclicality of the equity premium: essentially, because non-stockholders are very poor and poorly insured, they become effectively more risk averse during recessions when their wealth falls even further. Therefore, stockholders provide more insurance to these agents and bear more risk during these periods. This leads them to demand a higher ex ante premium to hold the equity risk. Another appealing implication of this model is the fairly smooth interest rate process generated by the model despite the very low EIS of the majority of households (non-stockholders). This result is due to the higher EIS of the stockholders who are on the other side of the bond market.

I have also investigated the extent to which the labor supply decision can be endogenized in this framework. Cobb-Douglas utility gave rise to some counterfactual implications and therefore did not seem to offer a promising direction. In contrast, GHH preferences did consecutive months and then take the absolute value. If I instead take the absolute value of monthly transactions first and then add up, the reported figure changes very little: it rises from $1.9 \%$ to $1.97 \%$.

${ }^{24}$ To see this, note that $E\left(\frac{\left|B-P^{f} B^{\prime}\right|}{\mu}\right) / E(C s)=4.9 \%$. 
not cause deterioration in asset pricing implications compared to the inelastic labor case. At the same time, the model's implications for some key business cycle statistics, such as the volatilities of consumption and investment, needs improvement. Therefore, the present model makes only modest progress in tackling these well-known shortcomings shared by many macro-asset pricing models.

A limitation of the present model is that it abstracts from long-run growth. Essentially, I assume that the economy is stationary in levels to circumvent the difficulties associated with obtaining a stationary wealth distribution with preference heterogeneity and long-run growth. Chan and Kogan (2002) are able to generate a stationary wealth distribution by introducing "benchmark consumption levels" into preferences. Although incorporating a similar idea into this framework would be a valuable extension, this is beyond the scope of the present analysis and remains an important area for extension of this model.

Finally, there are many parallels between the asset pricing results of this paper and those obtained in the external habit model of Campbell and Cochrane (1999). It turns out that these similarities point to a deeper connection between the two frameworks: indeed, the limited participation model studied in this paper has a reduced form representation that is very similar to Campbell and Cochrane's model, where the "external habit stock" in their framework corresponds to the consumption of non-stockholders in the present model. However, these similarities do not extend to the macroeconomic and policy implications of the two models, so the limited participation model should not be interpreted as providing micro-foundations for the particular habit specification used by these authors. These links between the two frameworks are explored in detail in Guvenen (2009).

I hope that these results would also encourage further research on the reasons behind limited participation, which is not addressed in this paper. ${ }^{25}$ Furthermore, given the central role played by limited participation in this model, another important research avenue is to investigate the consequences of the recent trends in participation observed in most countries for asset prices as well as for wealth inequality and welfare.

\footnotetext{
${ }^{25}$ Recently, Gomes and Michaelides (2008) have constructed a life-cycle model where individuals pay a one-time fixed cost to become a stockholder and argued that in this setting limited participation has a much smaller impact on asset prices. Their conclusion does not follow from the endogeneity of participation per se, because one can introduce a one-time cost into the present framework and show that it results in individuals with high EIS to enter the stock market whereas those with low EIS stay out. With a cost of appropriate magnitude, the resulting equilibrium is identical to the one studied here. (Further calculations on this fixed cost are available upon request.) The difference instead appears to come from some of the calibration choices made by these authors.
} 


\section{References}

[1] Ait-Sahalia, Y., J. Parker, and M. Yogo (2004): "Luxury Goods and the Equity Premium," Journal of Finance, 59, 2959-3004.

[2] Attanasio, O., J. Banks, and S. Tanner. (2002): "Asset Holding and Consumption Volatility," Journal of Political Economy, 110, 771-92.

[3] Bansal, R. and A. Yaron (2004): "Risks for the Long-Run: A Potential Resolution of Asset Pricing Puzzles," Journal of Finance, 59, 1481-1509.

[4] Barsky, B., F. Juster, M. Kimball, and M. Shapiro (1997): "Preference Parameters and Behavioral Heterogeneity: An Experimental Approach in the Health and Retirement Survey," Quarterly Journal of Economics, 112, 537-579.

[5] Basak, S., and D. Cuoco (1998): "An Equilibrium Model with Restricted Stock Market Participation," Review of Financial Studies, 11, 309-341.

[6] Blundell, R., M. Browning, and C. Meghir (1994): "Consumer Demand and the LifeCycle Allocation of Household Expenditures," Review of Economic Studies, 61, 57-80.

[7] Boldrin, M., L. Christiano, and J. Fisher (2001): "Habit Persistence, Asset Returns, and the Business Cycle," American Economic Review, 91, 149-166.

[8] Browning, M., and T. Crossley (2000): "Luxuries are Easier to Postpone: A Proof," Journal of Political Economy, 108, 1022-26.

[9] Campanale, C., R. Castro, and G. Clementi (2007): "Asset Pricing in a Production Economy with Chew-Dekel Preferences," Unpublished Manuscript, Stern School of Business, New York University.

[10] Campbell, J. Y. (1999): "Asset Prices, Consumption, and the Business Cycle," in Handbook of Macroeconomics, ed. by J. Taylor and M. Woodford, Vol. 1, Amsterdam: NorthHolland, 1231-1303.

[11] Campbell, J., and J. H. Cochrane (1999): "By Force of Habit: A Consumption Based Explanation of Aggregate Stock Market Behavior," Journal of Political Economy, Vol 107, pp. 205-251.

[12] Campbell, J. Y., and R. J. Shiller (1988): "Stock Prices, Earnings and Expected Dividends," Journal of Finance, 43, 661-76.

[13] Chan, Y., and L. Kogan (2002): "Catching Up with the Joneses: Heterogeneous Preferences and the Dynamics of Asset Prices," Journal of Political Economy, 110, 1255-85.

[14] Chou, R., R. F. Engle and A. Kane (1992): "Measuring Risk Aversion From Excess Returns on a Stock Index, Journal of Econometrics, 52, 210-224. 
[15] Christiano, L. J., and J. D. M. Fisher (1998): "Stock Market and Investment Good Prices: Implications for Macroeconomics, Unpublished Manuscript, Northwestern University.

[16] Christiano, L. , M. Eichenbaum, and C. L. Evans (2005): "Nominal Rigidities and the Dynamic Effects of a Shock to Monetary Policy," Journal of Political Economy, 113, $1-45$.

[17] Domeij, D., and M. Floden (2006). "The Labor-Supply Elasticity and Borrowing Constraints: Why Estimates are Biased," Review of Economic Dynamics, 9, 242-62.

[18] Danthine, J-P., and J. Donaldson (2002): "Labor Relations and Asset Returns," Review of Economic Studies, 69, 41-64.

[19] Epstein, L. G. (1988): "Risk Aversion and Asset Prices," Journal of Monetary Economics, 22, 179-192.

[20] Greenwood, J., Z. Hercowitz, and G. W. Huffman (1988): "Investment, Capacity Utilization, and the Real Business Cycles, American Economic Review, 78, 402-417.

[21] Gomes, F., and A. Michaelides (2008): "Asset Pricing with Limited Risk Sharing and Heterogeneous Agents," Review of Financial Studies, 21, 415-448.

[22] Guvenen, F. (2006): "Reconciling Conflicting Evidence on the Elasticity of Intertemporal Substitution: A Macroeconomic Perspective," Journal of Monetary Economics, 53, 1451-1472.

[23] Guvenen, F. (2009): "Limited Stock Market Participation versus External Habit: An Intimate Link", Unpublished Manuscript, University of Minnesota.

[24] Investment Company Institute (2002): "Equity Ownership in America," available online at http://www.ici.org/statements/res.

[25] Jermann, U. J. (1998): "Asset Pricing in Production Economies," Journal of Monetary Economics, 41, 257-275.

[26] Kimball, M., and M. Shapiro (2003): "Labor Supply: Are the Income and Substitution Effects Both Large or Both Small?" Unpublished Manuscript, University of Michigan.

[27] Krusell, P., and A. A. Smith, Jr. (1997): "Income and Wealth Heterogeneity, Portfolio Choice, and Equilibrium Asset Returns," Macroeconomic Dynamics, 1, 387-422.

[28] Lettau, M. and H. Uhlig (2000): "Can Habit Formation Be Reconciled with Business Cycle Facts?" Review of Economic Dynamics, 3, 79-99.

[29] Mankiw, N. G., and S. P. Zeldes (1991): "The Consumption of Stockholders and Nonstockholders," Journal of Financial Economics, 29, 97-112.

[30] Masulis, R. W. (1988): "The Debt-Equity Choice," Institutional Investor Series in Finance, Ballinger Press. 
[31] Mehra, R., and E. C. Prescott (1985): "The Equity Premium: A Puzzle," Journal of Monetary Economics, 15, 145-161.

[32] Poterba, J., and A. A. Samwick (1995): "Stock Ownership Patterns, Stock Market Fluctuations, and Consumption," Brookings Papers on Economic Activity, 26, 295-373.

[33] Saito, M. (1995): "Limited Participation and Asset Pricing," Unpublished Manuscript, University of British Columbia.

[34] Schwert, G. W. (1989): "Why Does Stock Market Volatility Change Over Time?" Journal of Finance, 44, 1115-1153.

[35] Storesletten, K., C. Telmer, and A. Yaron (2007): "Asset Pricing with Idiosyncratic Risk and Overlapping Generations," Review of Economic Dynamics, 10, 519-48.

[36] Tallarini, T. (2000): "Risk sensitive Business Cycles," Journal of Monetary Economics, $45,507-532$.

[37] Uhlig, H. (2006): "Macroeconomics and Asset Markets: Some Mutual Implications,"Unpublished Manuscript, University of Chicago.

[38] — (2007): "Leisure, Growth, and Long-run Risk," Unpublished Manuscript, University of Chicago. 